Louisiana State University

LSU Digital Commons

Faculty Publications

Department of Biological Sciences

$1-1-2015$

\title{
Cell type-specific responses to salinity - the epidermal bladder cell transcriptome of Mesembryanthemum crystallinum
}

\author{
Dong $\mathrm{Ha}$ Oh \\ Louisiana State University \\ Bronwyn J. Barkla \\ Southern Cross University \\ Rosario Vera-Estrella \\ Instituto de Biotecnología de la UNAM \\ Omar Pantoja \\ Instituto de Biotecnología de la UNAM \\ Sang Yeol Lee \\ Gyeongsang National University
}

See next page for additional authors

Follow this and additional works at: https://digitalcommons.Isu.edu/biosci_pubs

\section{Recommended Citation}

Oh, D., Barkla, B., Vera-Estrella, R., Pantoja, O., Lee, S., Bohnert, H., \& Dassanayake, M. (2015). Cell typespecific responses to salinity - the epidermal bladder cell transcriptome of Mesembryanthemum crystallinum. New Phytologist, 207 (3), 627-644. https://doi.org/10.1111/nph.13414

This Article is brought to you for free and open access by the Department of Biological Sciences at LSU Digital Commons. It has been accepted for inclusion in Faculty Publications by an authorized administrator of LSU Digital Commons. For more information, please contact ir@lsu.edu. 


\section{Authors}

Dong Ha Oh, Bronwyn J. Barkla, Rosario Vera-Estrella, Omar Pantoja, Sang Yeol Lee, Hans J. Bohnert, and Maheshi Dassanayake 


\title{
Cell type-specific responses to salinity - the epidermal bladder cell transcriptome of Mesembryanthemum crystallinum
}

\author{
Dong-Ha Oh ${ }^{1}$, Bronwyn J. Barkla ${ }^{2}$, Rosario Vera-Estrella ${ }^{3}$, Omar Pantoja ${ }^{3}$, Sang-Yeol Lee ${ }^{4}$, Hans J. Bohnert ${ }^{5}$ and \\ Maheshi Dassanayake ${ }^{1}$
}

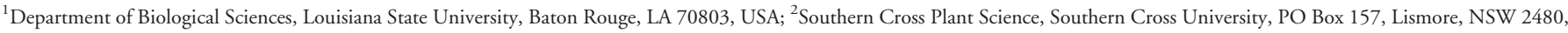

Australia; ${ }^{3}$ Instituto de Biotecnología, UNAM, A.P. 510-3, Colonia Miraval, Cuernavaca, MOR 62250, México; ${ }^{4}$ Division of Applied Life Science, Gyeongsang National University,

Jinju 660-701, South Korea; ${ }^{5}$ Departments of Plant Biology and of Crop Sciences, University of Illinois at Urbana-Champaign, Urbana, IL, USA

Authors for correspondence:

Bronwyn J Barkla

Tel: +61266203159

Email: bronwyn.barkla@scu.edu.au

Maheshi Dassanayake

Tel: +1 2255780960

Email: maheshid@lsu.edu

Received: 22 January 2015

Accepted: 8 March 2015

New Phytologist (2015) 207: 627-644

doi: 10.1111/nph.13414

Key words: cell type-specific, Crassulacean acid metabolism (CAM), epidermal bladder cell (EBC), Mesembryanthemum crystallinum, RNAseq, salt stress, transcriptome, vacuole.

\section{Summary}

- Mesembryanthemum crystallinum (ice plant) exhibits extreme tolerance to salt. Epidermal bladder cells (EBCS), developing on the surface of aerial tissues and specialized in sodium sequestration and other protective functions, are critical for the plant's stress adaptation. We present the first transcriptome analysis of EBCs isolated from intact plants, to investigate cell type-specific responses during plant salt adaptation.

- We developed a de novo assembled, nonredundant EBC reference transcriptome. Using RNAseq, we compared the expression patterns of the EBC-specific transcriptome between control and salt-treated plants.

- The EBC reference transcriptome consists of 37341 transcript-contigs, of which $7 \%$ showed significantly different expression between salt-treated and control samples. We identified significant changes in ion transport, metabolism related to energy generation and osmolyte accumulation, stress signalling, and organelle functions, as well as a number of lineagespecific genes of unknown function, in response to salt treatment.

- The salinity-induced EBC transcriptome includes active transcript clusters, refuting the view of EBCs as passive storage compartments in the whole-plant stress response. EBC transcriptomes, differing from those of whole plants or leaf tissue, exemplify the importance of cell typespecific resolution in understanding stress adaptive mechanisms.

\section{Introduction}

The annual succulent Mesembryanthemum crystallinum (ice plant) is a model halophyte which has been used to search for physiological, biochemical, and molecular mechanisms fundamental to plant salt and water stress responses (Lüttge et al., 1978; Adams et al., 1998; Bohnert \& Cushman, 2000; Barkla et al., 2009). The adult ice plant reveals a series of adjustments to cope with stress, including dramatic metabolic changes from $\mathrm{C}_{3}$ to Crassulacean acid metabolism (CAM), in response to a variety of conditions, such as high photon flux density, drought, and salinity (Adams etal., 1998; Winter \& Holtum, 2007). CAM permits the net uptake of $\mathrm{CO}_{2}$ at night, and thus significantly increases water use efficiency (Cushman \& Bohnert, 1999).

One outstanding trait of M. crystallinum is the presence of epidermal bladder cells (EBCs) on the aerial parts of the plant. These nonglandular, nonsecreting, single-cell trichomes line the plant's leaves, stems, and flower buds. EBCs remain compressed to the epidermal surface in unstressed plants, but expand to comprise up to $25 \%$ of the total aerial volume once the plants have responded to stresses (Steudle et al., 1975). Fully developed
EBCs accumulate $\mathrm{Na}^{+}$, with concentrations up to $>1 \mathrm{M}$ measured in EBC extracts (Adams et al., 1992), and also compatible solutes, predominantly ononitol and pinitol (Paul \& Cockburn, 1989; Vernon \& Bohnert, 1992a). A mutational study implicated the presence of EBCs in M. crystallinum as a substantial contributing factor for salt tolerance (Agarie et al., 2007). Enlarged EBCs may function in UV protection and defense by accumulating flavonoids and betacyanins, and act as reflectors protecting the underlying mesophyll cells from heat damage (Vogt et al., 1999; Ibdah et al., 2002).

Mesembryanthemum crystallinum expressed sequence tags (ESTs) have been used to compare gene expression in different developmental states, stress conditions, and diurnal cycles (Kore-eda et al., 2004; Cushman et al., 2008). Recently, proteomic approaches identified salt-responsive proteins from $M$. crystallinum leaves (Cosentino et al., 2013). These studies measured molecular signatures in the context of the entire leaf, ignoring any cell type-specific processes and stress responses. The salt stress response is strikingly illuminated by the EBCs more than by any other cell type in M. crystallinum. Yet biochemical or molecular functions underlying the physiological and morphological changes in this specialized cell type have to date not been studied separately from the rest of the leaf tissue. 
Despite the many biochemical and molecular data sets that have been produced (Barkla etal., 2013; Borland et al., 2014), few attempts have been made to dissect the role of the cell typespecific response in salt stress adaptation. A cell type-specific transcriptome atlas in rice (Oryza sativa) (Jiao et al., 2009) confirmed that many cell-specific mRNAs are not detectable in whole-tissue or whole-organ samples. Obtaining cell type-specific transcriptomes remains a challenge despite the recognized need for microgenomics to access cell type-specific gene expression (Bailey-Serres, 2013).

A high-throughput method was developed to extract sap from EBCs, enabling the resolution of functional changes of this unique cell type (Barkla et al., 2012). In a first attempt to explore the proteome of EBC sap from salt-treated plants, we identified proteins involved in ion and water homeostasis and found evidence for active participation in CAM by EBCs (Barkla et al., 2012, 2013). These studies suggested that EBCs are metabolically highly active, refuting previous views of EBCs as mere metabolically passive reservoirs of carbon (as inositols and malate, for example), salt, and water (Lüttge et al., 1978).

We report here the transcriptome of M.crystallinum EBCs from mature plants. We have assembled an EBC-specific reference transcriptome de novo, and have quantified transcript levels with and without plant reorganization in response to salt stress. Our results indicate the salinity-dependent activation of metabolic pathways in EBCs that may lead to compatible solute and pigment accumulation, as well as maintenance of a large arsenal of transporter systems. Our results also reveal EBC-specific pronounced transcriptome responses to salt in a number of precisely defined pathways. These responses differ from canonical plant 'salt stress' responses, and mirror changes in signal transduction and organelle functions, probably as a consequence of the saltinduced accumulation of osmolytes and the drastic anatomical modification of this particular cell type.

\section{Materials and Methods}

\section{Plant material}

Mesembryanthemum crystallinum L. plants derived from material originally collected by Winter et al. (1978) were grown in MetroMix510 soil (SunGro Horticulture, Bellevue, WA, USA), in a glasshouse under natural irradiation and photoperiod, where photosynthetic photon flux density reached a midday maximum of $1300 \mu \mathrm{mol} \mathrm{m}^{-2} \mathrm{~s}^{-1}$. Temperature was maintained at $25 \pm 3^{\circ} \mathrm{C}$. Plants were watered daily, and half-strength Hoagland's medium (Hoagland \& Arnon, 1950) was supplied weekly. $\mathrm{NaCl}$ treatment $(200 \mathrm{mM})$ was initiated $6 \mathrm{wk}$ after germination for a period of $14 \mathrm{~d}$.

\section{Extraction of EBC sap}

EBC sap was obtained from cells in stems and on the leaf abaxial epidermal surface by vacuum aspiration using a fine-gauge insulin needle $(27 \mathrm{G} ; 13 \mathrm{~mm})$ attached to a collection reservoir maintained on ice. The needle was oriented horizontally to the leaf or stem axis to avoid removing sap from underlying tissue. The procedure was visualized using a Nikon SMZ645 stereo-microscope (Nikon, Mexico City, Mexico). The sap from c. 3000 EBCs from a single mock- or salt-treated plant was pooled to obtain $c .1 \mathrm{ml}$ of sample. Two biological replicates were harvested for each condition. Sap was collected at the end of the dark phase, and tissue was kept in the dark until the collection.

\section{Salt responses of EBCS}

The osmolarity of the EBC sap was measured in 50- $\mu$ samples with a cryoscopic osmometer (Osmomat030; Genotec, Gangelt, Germany). $\mathrm{Na}^{+}$and $\mathrm{K}^{+}$concentrations were determined using Flame photometry (Model 943; Instrumentation Laboratory, Lexington, MA, USA). Anthocyanin content in EBC sap was measured as described by Neff \& Chory (1998), by measuring absorbance of the solution at 530 and $657 \mathrm{~nm}$ using a diode array spectrophotometer (Hewlett Packard, Palo Alto, CA, USA), after extraction with an equal volume of acidified methanol $(1 \% \mathrm{HCl})$, incubation at $4{ }^{\circ} \mathrm{C}$ for $1 \mathrm{~h}$, and centrifugation. Betacyanins and betaxanthins were measured according to Stintzing et al. (2003). EBC sap samples were mixed with an equal volume of $100 \%$ ethanol, and absorbance of supernatants was determined at 480 and $538 \mathrm{~nm}$, after centrifugation.

\section{Sequencing, assembly, and annotation of the reference transcriptome}

Total RNA was extracted from the EBC sap using the RNeasy Plant Mini kit (Qiagen, Mexico City, Mexico). RNA-sequencing (RNA-seq) libraries were prepared using the TruSeq Stranded RNA Sample Prep Kit (Illumina, San Diego, CA, USA). Libraries from control and salt-treated samples, with two biological replicates, were bar-coded and sequenced in a single Illumina HiSeq2000 flowcell, generating >41 million high-quality 100-nucleotide (nt) single-end RNA-seq reads per sample.

For the de novo reference transcriptome assembly, all RNA-seq reads were pooled and used as input for the Trinity pipeline (version 'trinityrnaseq_r2012-01-25', Kcov $=2$ and $-S$ option for strand specificity; Haas et al., 2013). After removing contaminants, artefacts, and contigs with low read support (Table 1), all assembled transcript contigs showing $>95 \%$ sequence identity over $>70 \%$ of the total length were clustered using all-to-all BLASTN. We selected a representative transcript containing the longest continuous open reading frames (ORFs) for each cluster to generate a nonredundant Mesembryanthemum crystallinum epidermal bladder cell (McEBC) transcriptome.

Annotation was based on best BLASTN hits found in the National Center for Biotechnology Information (NCBI) database 'refseq_rna' (April 2014), as well as the TAIR10 Arabidopsis gene model sequence, with $10^{-5}$ as the e-value cut-off. Sequence comparison with M. crystallinum full-length cDNAs (NCBI, November 2013) and ESTs (http://compbio.dfci.harvard.edu/tgi/, July 2008) was performed using NuCMER (-minmatch 11 -mincluster 25; Kurtz et al., 2004). ORFs in each contig were identified with TRAnSDECODER (http://transdecoder.sourceforge.net/). The 
Table 1 De novo assembly of a Mesembryanthemum crystallinum epidermal bladder cell (McEBC) transcriptome

\begin{tabular}{|c|c|c|c|c|c|c|}
\hline \multirow[b]{2}{*}{ Assemblies } & \multicolumn{3}{|c|}{ Transcriptome stats } & \multicolumn{3}{|c|}{ RNA-seq read mapping stats ${ }^{\mathrm{a}}$} \\
\hline & $\begin{array}{l}\text { Number of } \\
\text { transcript } \\
\text { contigs }\end{array}$ & $\begin{array}{l}\text { Median } \\
\text { contig } \\
\text { length }^{b}\end{array}$ & $\begin{array}{l}\text { Total base } \\
\text { assembled } \\
\text { (Mbase) }\end{array}$ & $\begin{array}{l}\text { Total mapped } \\
\text { reads }(\%)\end{array}$ & $\begin{array}{l}\text { Uniquely mapped } \\
\text { reads (\%) }\end{array}$ & $\begin{array}{l}\text { Reads mapped to } \\
\text { multiple contigs (\%) }\end{array}$ \\
\hline Trinity assembly ${ }^{c}$ & 101077 & 769 & 119.0 & $86.96 \pm 5.67$ & $64.18 \pm 3.88$ & $22.78 \pm 1.81$ \\
\hline After removing nonplant contigs ${ }^{\mathrm{d}}$ & 100044 & 778 & 118.4 & $86.52 \pm 5.79$ & $63.78 \pm 3.99$ & $22.74 \pm 1.82$ \\
\hline After removing missense contigs ${ }^{\mathrm{e}}$ & 95423 & 825 & 115.7 & $86.32 \pm 5.77$ & $63.63 \pm 3.97$ & $22.68 \pm 1.82$ \\
\hline After removing low-abundance contigs ${ }^{\dagger}$ & 85492 & 996 & 113.3 & $86.27 \pm 5.76$ & $63.59 \pm 3.97$ & $22.68 \pm 1.82$ \\
\hline After removing redundant contigs ${ }^{\mathrm{g}}$ & 37341 & 665 & 39.4 & $82.48 \pm 5.48$ & $82.40 \pm 5.44$ & $0.08 \pm 0.04$ \\
\hline
\end{tabular}

${ }^{\mathrm{a}}$ Mean \pm SE from four RNA-seq samples (control and salt-treated; two biological replicates) are shown. All RNA-seq samples include at least 41.99 million high-quality reads. RNA-seq reads were mapped to the reverse strand of the contigs from each assembly.

${ }^{\mathrm{b}}$ For all assemblies, the minimum and maximum contig lengths were $201 \mathrm{nt}$ and $12252 \mathrm{nt}$, respectively.

'Strand-specific assembly with minimum Kmer coverage 2.

${ }^{\mathrm{d}}$ Contigs showing BLASTN hit score with e-value $<10^{-5}$ only to a nonplant RNA sequence were removed.

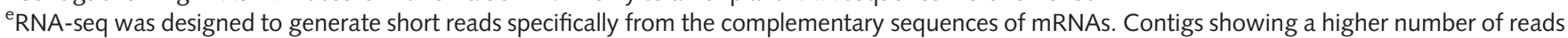
mapped to the forward strand than the complementary strand were considered as artifacts and removed.

${ }^{f}$ Contigs supported with no more than 10 RNA-seq reads were removed.

${ }^{g}$ See the Materials and Methods section and Supporting Information Fig. S1 for details.

transcriptome assembly and annotation were deposited at the NCBI (BioProject ID: PRJNA260050).

\section{RNA-seq analysis}

RNA-seq reads from each sample were aligned to the McEBC transcriptome using BowTIE (Langmead etal., 2009), with the seed length set to $50 \mathrm{nt}$. The number of reads uniquely aligned to each contig was counted for each sample. Contigs with significantly different uniquely mapped RNA-seq reads between control and salt-treated samples were identified as differently expressed transcript contigs (DETs), based on false discovery rate (FDR) $<0.01$ (Benjamini-Hochberg correction), using the DESEQ pipeline (Anders \& Huber, 2010). We also calculated reads mapped per kilobase of transcript contig per million reads (RPKM) for each contig, following Mortazavi et al. (2008). Gene ontology (GO) terms enriched in DETs were analysed via BINGO (Maere et al., 2005), using the GO annotation assigned to the most similar Arabidopsis homolog of each DET. RNA-seq results for selected transcript contigs were visualized using INTEGRATIVE GeNOME VIeWER (Thorvaldsdóttir et al., 2012).

\section{Results}

\section{Salt responses in McEBC}

EBCs were present at all stages of development on the aerial tissue of the M. crystallinum plant. In unstressed adult plants the EBCs were small and appressed to leaf, stem, or flower bud surfaces (Fig. 1a,b; control). In salt-treated plants of the same age, the cells expanded and appeared as liquid-filled balloons (Fig. 1a-c; salt). When plants were exposed to continuous long-term stress, EBCs accumulated visible amounts of pigments (Fig. 1d).

Treatment of plants with $200 \mathrm{mM} \mathrm{NaCl}$ resulted in a more than three-fold increase in the osmolarity of EBC sap isolated from leaves and stems, compared with the mock-treated control
(Fig. 2a). $\left[\mathrm{Na}^{+}\right]$in the EBC sap was 87.7 and $820 \mathrm{mM}$ in the control and salt-treated samples, respectively, while $\left[\mathrm{K}^{+}\right]$showed no significant differences (Fig. 2a). To determine the nature of pigment accumulation (Fig. 1d), we measured the amounts of anthocyanins, betacyanins, and betaxanthins (Fig. 2b, Supporting Information Fig. S1). While anthocyanins were unchanged by salt treatment, betacyanins and betaxanthins were present in larger amounts in untreated samples and further increased by 2.4and 7.1-fold, respectively, following salt treatment (Fig. 2b).

\section{De novo assembly and annotation of the McEBC transcrip- tome}

We sequenced RNA samples derived from extracts of EBCs isolated from 8-wk-old M. crystallinum plants treated for 2 wk with mock solution for control or with $200 \mathrm{mM} \mathrm{NaCl}$. Two biological repeats were prepared for each condition. RNA-seq reads pooled from all biological replicates were used for de novo Trinity assembly, to produce a reference transcriptome. The initial assembly contained 101077 contigs. Mapping of RNA-seq reads to the assembled transcript contigs using BOWTIE revealed c. $22 \%$ of total reads were mapped to multiple contigs, indicating the presence of redundant assembled sequences within the transcriptome (Table 1). After filtering out nonplant, missense, and low-abundance contigs, the remaining contigs were subjected to clustering and cleaning of redundant sequences, as described in the Materials and Methods section and Fig. S2. This generated a reference McEBC transcriptome of 37341 transcript contigs with the median contig length of $665 \mathrm{nt}$. Compared with the initial transcriptome assembly, RNA-seq reads mapped to multiple contigs were reduced to $<1.2 \%$, indicating that the curated reference transcriptome is nonredundant (Table 1 ).

The nonredundant McEBC transcriptome was annotated based on sequence similarity as described in the Materials and Methods section (Tables 2, S1). When compared with the NCBI reference RNA sequence database (as of April 2014), 16984 
(a)

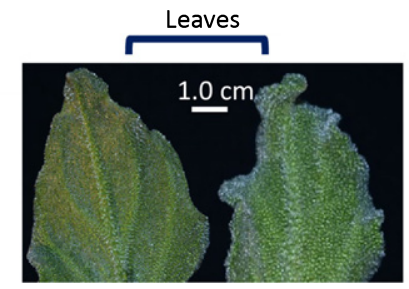

Control

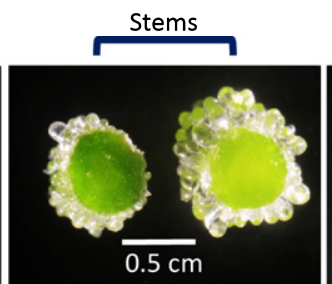

Control Salt

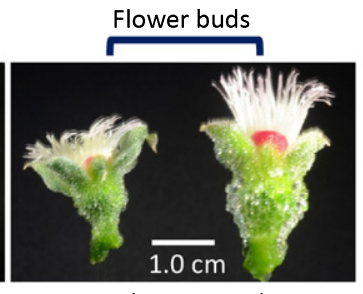

Control

Salt

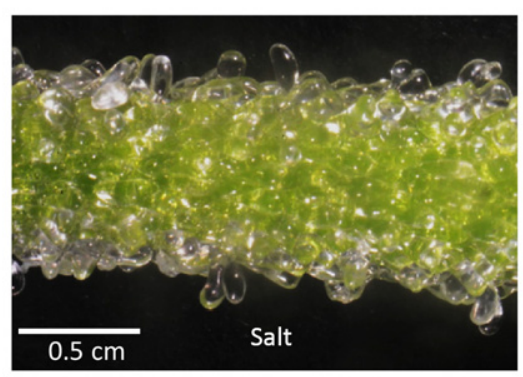

(c)

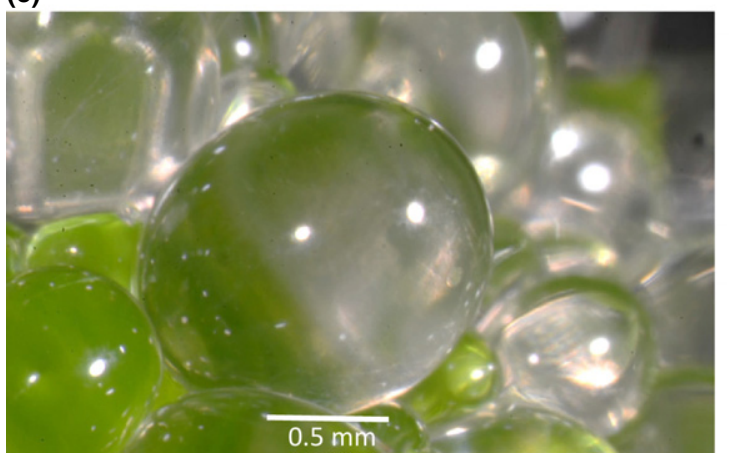

(d)
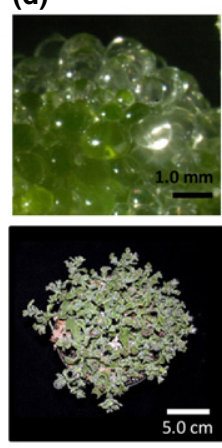

Control
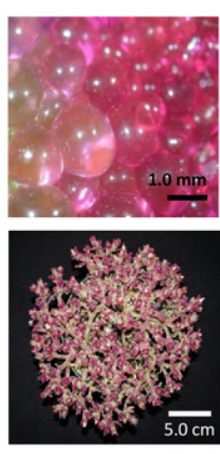

Salt
Fig. 1 Epidermal bladder cells (EBCs) from Mesembryanthemum crystallinum. (a) EBCs on the aerial parts of a 8-wk-old plant, including the leaves, stems and flower buds, from control and salt-treated $(200 \mathrm{mM} \mathrm{NaCl}$ for 2 wk) plants. (b) Cells are appressed to the stem surface under control conditions (control) but enlarge when plants are salttreated (salt). (c) Magnification of a single EBC after salt treatment. (d) EBCs accumulate pigments when exposed to high concentrations of salt for prolonged periods (upper and lower right), while unstressed plants only accumulate minimal amounts of the pigments, primarily at leaf tips and on flower buds (upper and lower left). Plants shown are $13 \mathrm{wk}$ old and have been salttreated for $7 \mathrm{wk}$. contigs showed a BLASTN hit with a plant sequence (e-value $<10^{-5}$ ), with $c .70 \%$ of contigs showing the highest similarity to sequences derived from Vitis vinifera (8352 contigs), Populus trichocarpa (1849 contigs), or Ricinus communis (1534 contigs). Comparison with the TAIR10 Arabidopsis annotation identified 14521 contigs, or $38.9 \%$ of the total, showing a BLASTN hit $\left(\mathrm{e}<10^{-5}\right)$ with an Arabidopsis gene model (Table 2). Among all contigs, $25670(68.7 \%)$ contained an ORF encoding a polypeptide longer than 50 aa (Table 2). The McEBC transcriptome was also compared with the $145 \mathrm{M}$. crystallinum full-length cDNAs and 10399 unique ESTs, retrieved from NCBI and The Institute for Genomic Research databases, respectively. In total, 100 fulllength cDNAs and 5650 ESTs showed $>70 \%$ overlap with a contig in the McEBC transciptome, with at least $98 \%$ sequence identity. Among them, 63 cDNAs and 4042 ESTs showed a perfect or near-perfect match $(>98 \%$ overlap and $>98 \%$ identity; Table 2).

\section{Salt-regulated DET contigs in the McEBC transcriptome}

We used the DESEQ package to compare the two biological replicates of control and salt-treated samples to identify salt-regulated DETs, based on the number of RNA-seq reads uniquely mapped to each transcript contig in the McEBC transcriptome. We identified 2490 up-regulated and 2849 down-regulated DETs with expression significantly $($ FDR $<0.01)$ altered in response to salt treatment (Fig. 3a). More than 86\% (4595) of all DETs contained an ORF. Among them, 1028 did not show significant sim-

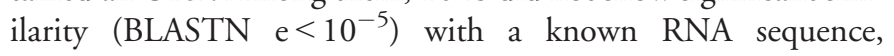
probably encoding lineage-specific peptides (Fig. 3b).

To access the abundance of transcript contigs in the McEBC transcriptome, we quantified RPKM of each transcript contig. We found lineage-specific transcripts enriched among rarely expressed transcripts. When ranked from the most abundant to the least abundant transcripts, the top 25\% most abundant transcripts include $<5 \%$ of the total lineage-specific transcripts. By contrast, the remaining $21 \%, 36 \%$ and $38 \%$ of the lineage-specific transcripts were found in the second, third and fourth quartiles, respectively (Fig. 3c). It is possible that the majority of these lineage-specific transcript contigs with low expression represent fragments of transposable elements, which show greater sequence variation compared with nontransposon genes.

The top 60 most abundant transcript contigs, ranked based on their average RPKMs in the control and salt-treated samples, are listed in Table 3. Among them, a number of transcripts encoding abscisic acid (ABA) - and dehydration-induced proteins, nonspecific lipid transport proteins, defense-related proteins, and chlorophyll alb (Chlalb)-binding proteins were down-regulated by salt treatment (e.g. ranks 1, 2, 3, 7, 11, 13, 16 and 17, in Table 3). By contrast, those encoding enzymes related to stress 

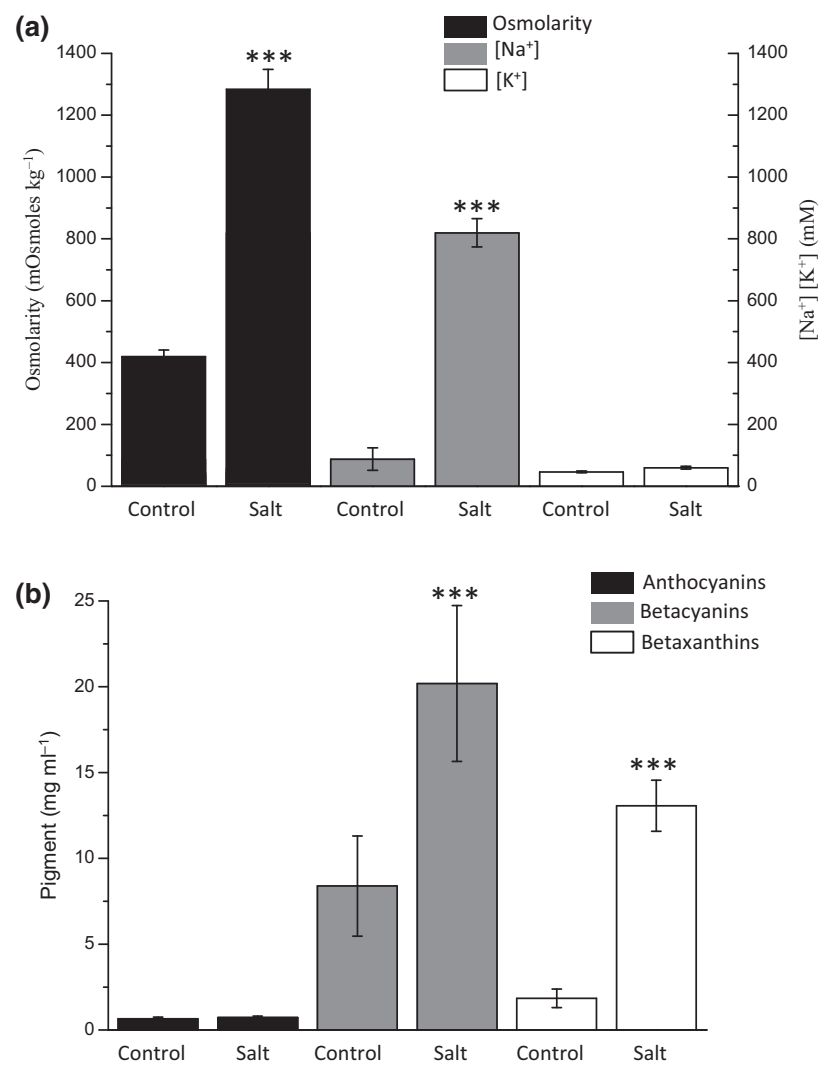

Fig. 2 Salt stress responses of epidermal bladder cells (EBCs). (a) Osmolarity, $\mathrm{Na}^{+}$and $\mathrm{K}^{+}$measurements and (b) anthocyanin, betacyanin and betaxanthin contents of EBC sap isolated from Mesembryanthemum crystallinum plants grown in the absence (control) or presence (salt) of $200 \mathrm{mM} \mathrm{NaCl}$ for $2 \mathrm{wk}$. Shown are the mean \pm SD of 10 replicates. Unpaired two-tailed Student's $t$-test: $n=10 ; * * *, P<0.01$.

response and carbohydrate catabolism were up-regulated by salt treatment. These included a cysteine protease, a myo-inositol-1phosphate synthase (INPS), a pyruvate phosphate dikinase (PPDK), an aldolase, and a beta-amylase homolog (ranks 8, 23, 29, 35 and 41, respectively, in Table 3). A plasma membrane (PM) aquaporin homolog was ranked at 52, indicating that it was the most abundant among all transcripts encoding transporter/channel proteins, while its expression was not significantly affected by salt $(F D R=0.14$; Table 3$)$. A number of putative lineage-specific transcripts, showing similarity to $M$. crystallinum ESTs, but no significant similarity (BLASTN e $<10^{-5}$ ) to a known RNA sequence from any other species, were also found among the top 60 most abundant transcripts (ranks 21, 31, 42, 49, 53 and 57, in Table 3).

\section{Networks of GO terms enriched among DETs}

Approximately $60 \%$ of all salt-regulated DETs showed significant sequence similarity (BLASTN e $<10^{-5}$ ) with an Arabidopsis gene, enabling GO enrichment analysis on DETs, based on GO annotations of their Arabidopsis homologs. We selected 1234 up-regulated and 1669 down-regulated DETs showing sequence similarity in their ORF regions with Arabidopsis ORF sequences, and used BiNGO to identify and visualize GO terms
Table 2 Annotation of the reference Mesembryanthemum crystallinum McEBC transcriptome

\begin{tabular}{|c|c|c|}
\hline Category & Cutoff & $\begin{array}{l}\text { Numbers in } \\
\text { total } 37341 \\
\text { contigs }\end{array}$ \\
\hline $\begin{array}{l}\text { Shows BLASTN hit with } \\
\text { a plant refseq_rna } \\
\text { sequence }\end{array}$ & BLASTN e-value $<10^{-5}$ & 16984 \\
\hline $\begin{array}{l}\text { Shows BLASTN hit } \\
\text { with an Arabidopsis } \\
\text { gene model }\end{array}$ & BLASTN e-value $<10^{-5}$ & 14521 \\
\hline \multirow[t]{2}{*}{ Contains an $\mathrm{ORF}^{\mathrm{a}}$} & Deduced protein $\geq 100$ aa & 16652 \\
\hline & Deduced protein $\geq 50$ aa & 25670 \\
\hline \multirow{2}{*}{$\begin{array}{l}\text { Shows similarity with } \\
\text { a known } M \text {. crystallinum } \\
\text { full-length cDNA }\end{array}$} & $\begin{array}{l}>98 \% \text { identity, }>70 \% \\
\text { coverage }\end{array}$ & $100^{b}$ \\
\hline & $\begin{array}{l}>98 \% \text { identity, }>98 \% \\
\text { coverage }\end{array}$ & $63^{b}$ \\
\hline $\begin{array}{l}\text { Shows similarity with } \\
\text { a known }\end{array}$ & $\begin{array}{l}>98 \% \text { identity, }>70 \% \\
\text { coverage }\end{array}$ & $5650^{c}$ \\
\hline M. crystallinum EST & $\begin{array}{l}>98 \% \text { identity, }>98 \% \\
\text { coverage }\end{array}$ & $4042^{c}$ \\
\hline
\end{tabular}

ancluding partial open reading frames (ORFs), identified using TRANSDECODER.

${ }^{b}$ Out of 145 full-length M. crystallinum cDNA sequences retrieved from NCBI.

${ }^{\mathrm{C}}$ Out of 10399 nonredundant expressed sequence tags (ESTs) retrieved from TIGR (http://compbio.dfci.harvard.edu/tgi/).

enriched among them (Figs 4, S3, S4; Tables 4, S2, S3). Fig. 4 illustrates networks of GO terms enriched among DETs, constructed based on their parent-child relationships. A network consisting of 'transport' (GO:0006810), 'generation of precursor metabolites and energy' (GO:0006091), and their children was identified among GO terms enriched in up-regulated DETs. This network (Fig. 4a) included salt-induced DETs encoding components of the vacuolar proton transporting ATPase (vacuolar $\mathrm{H}^{+}$-ATPase (VHA)) and cation transporters, as well as enzymes in the glycolytic pathway (Table 4, BP-U3; Table S3). Similarly, there was enrichment of 'response to stimulus' (GO:0050896) and its child GO terms in DETs down-regulated by salt. This network (Fig. 4b) consisted of genes annotated as responsive to various biotic and abiotic stresses, especially salt and osmotic stresses (Table 4, BP-D1; Table S3).

Comparison between all networks for up- and down-regulated DETs identified distinct salt-regulated branches of GO networks (summarized in Table 4). For example, while the GO term 'response to stimulus' (GO:0050896) was overrepresented in both salt up- and down-regulated DETs, the overrepresentation was caused specifically by enrichment of child GO terms 'response to radiation' (GO:0009314) and 'response to hormone stimulus' (GO:0032870) for DETs up-regulated by salt. By contrast, 'response to salt stress' (GO:0009651), 'response to fungus' (GO:0009620), and 'response to water deprivation' (GO:0009414) were enriched in DETs down-regulated by salt (Table 4; BP-U1 and BP-D1). Similarly, distinct child GO terms of 'small molecule metabolic process' (GO:0044281) and 'transport' (GO:0006810) were enriched in DETs up- (Table 4; BP-U2 and BP-U3) as well as down-regulated (Table 4; BP-D2 and 
(a)

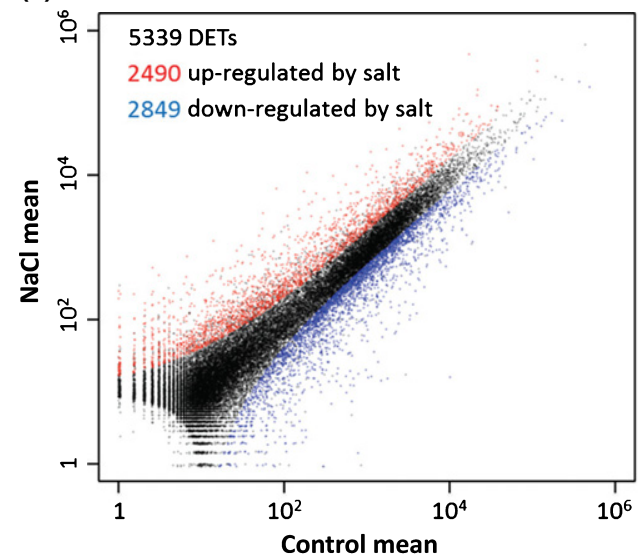

(b)

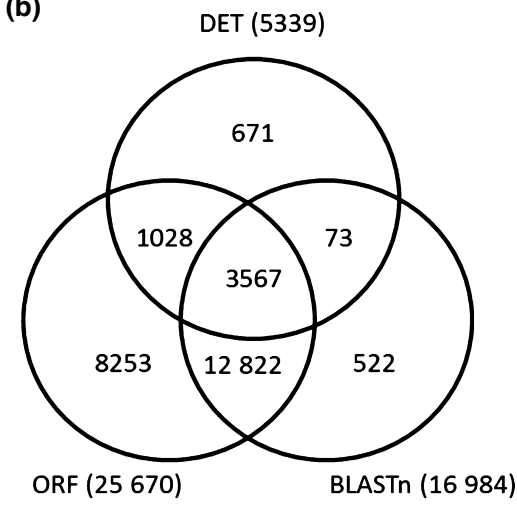

(c) No BLASTN hit (lineage-specific transcripts) BLASTN hit with a plant RNA sequence $\left(e<10^{-5}\right)$

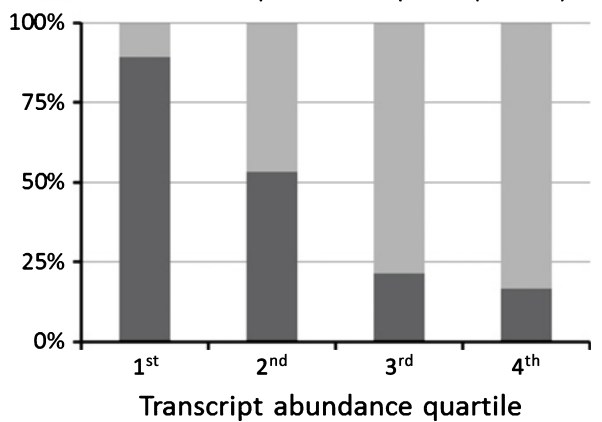

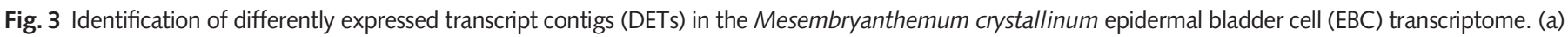

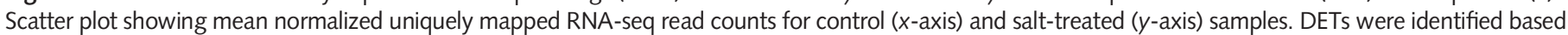

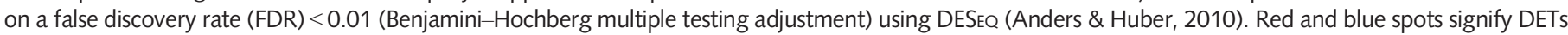

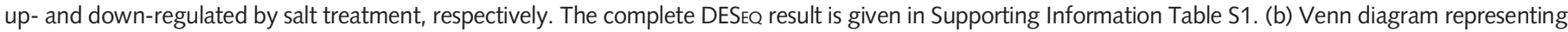
overlaps among DETs, transcript contigs containing an open reading frame (ORF) encoding a protein larger than 50 aa and transcript contigs showing a BLASTN hit with a known plant reference RNA or an Arabidopsis gene model sequence with an e-value cutoff of $10^{-5}$ (BLASTN). (c) The percentage of

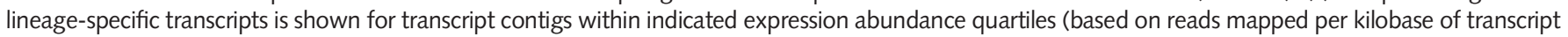

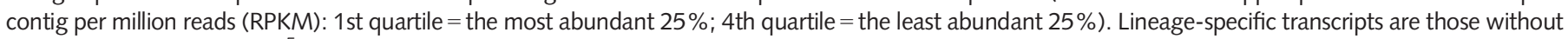
a BLASTN hit (e-value $<10^{-5}$ ) with any sequence in the National Center for Biotechnology Information (NCBI) reference RNA ('refseq_rna') database, as described in the Materials and Methods section.

BP-D3) by salt. For the GO terms in the category Cellular Component, different child terms of 'plastid' (GO:0009536) were overrepresented in DETs both up- and down-regulated by salt (Table 4; CC-U1 and CC-D1). In addition, 'vacuole' (GO:0005773) and its child GO terms were highly represented in salt-induced DETs, while 'endoplasmic reticulum' (GO:0005783), 'Golgi apparatus' (GO:0005794), 'plant-type cell wall' (GO:0009505) and 'tubulin complex' (GO:0045298) were overrepresented in DETs down-regulated by salt (Table 4; CC-U2 and CC-D2). Analysis of GO terms in the Molecular Function category revealed a similar result comparable to that for the Biological Process category (data not shown). In their entirety, the networks are presented in Figs S3 and S4, and transcript contigs included in each GO term are listed in Table S3.

\section{Salt response of the $\mathrm{MCEBC}$ transcriptome}

Based on GO enrichment analysis, we focused on gene families and pathways that highlighted different aspects of the collective salt response of the McEBC transcriptome. These included genes involved in ion transport, cellular energy metabolism, canonical stress signal transduction and responses, and intracellular organelle functions. Transcript contigs encoding proteins involved in each aspect are curated (Tables S4-S7), and RNA-seq results for representative transcripts are plotted as read abundance across the transcript model under control and salt-stressed conditions (Figs 5, 6).

Ion transport The salt response of ion transporters known to be involved in $\mathrm{Na}^{+}$transport and sequestration, including vacuolar proton pumps, is shown in Fig. 5(a) and Table S4. A homolog of the chloroplast-localized $\mathrm{Na}^{+}-H Y D R O G E N$ ANTIPORTER 1 (NHD1) was induced 2.5-fold by salt. While transcripts encoding full-length homologs of $\mathrm{Na}^{+}-\mathrm{H}^{+}$EXCHANGER 2 (NHX2) and SALT OVERLY SENSITIVE 1 (SOS1) were ranked in the top $10 \%$ most abundant transcripts (Table S1), their expression levels were not significantly affected by salt. Similarly, cation exchangers in the CATION $H^{+}$EXCHANGER (CHX) family were unaffected by salt, with the exception of a $C H X 19$ homolog 


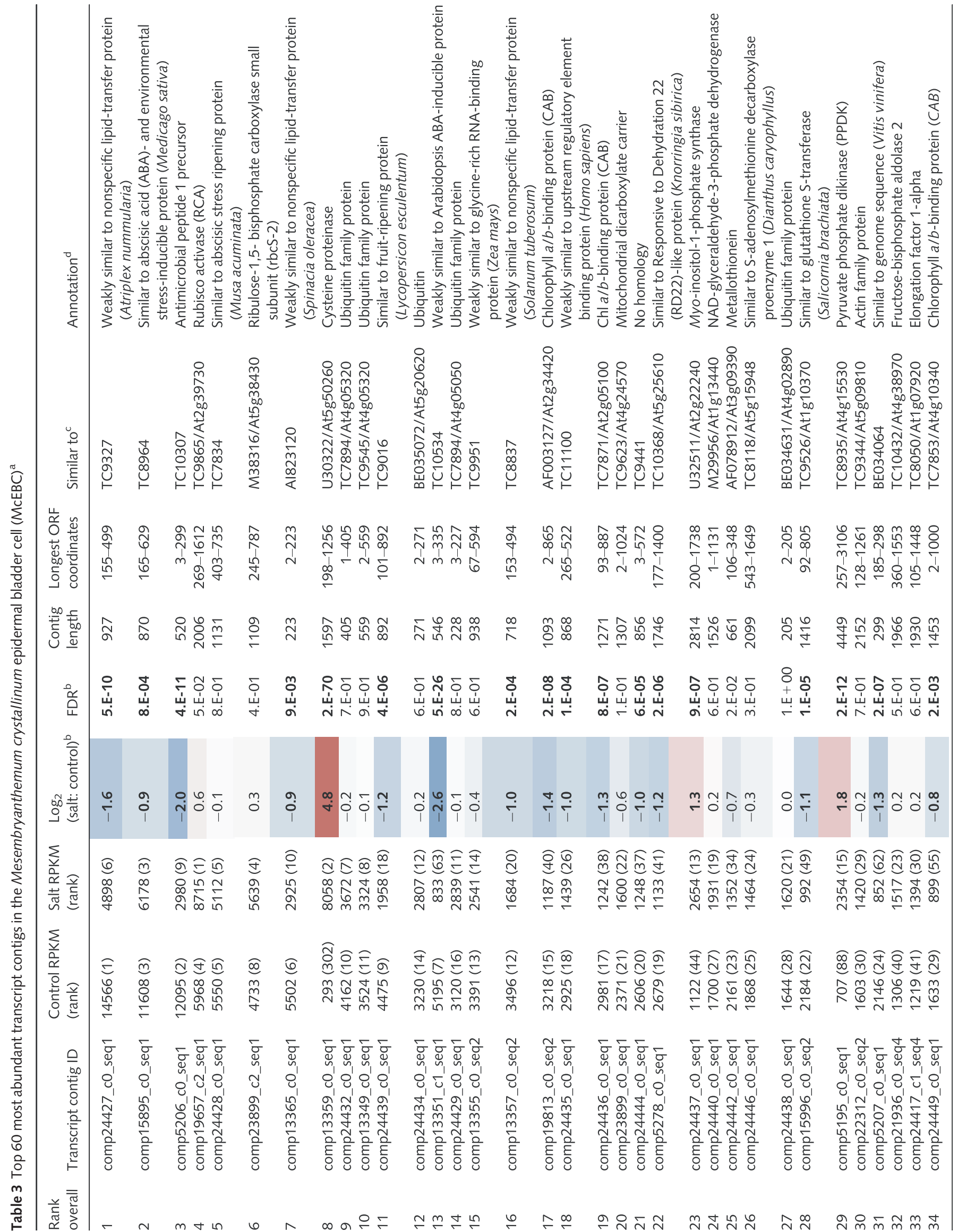




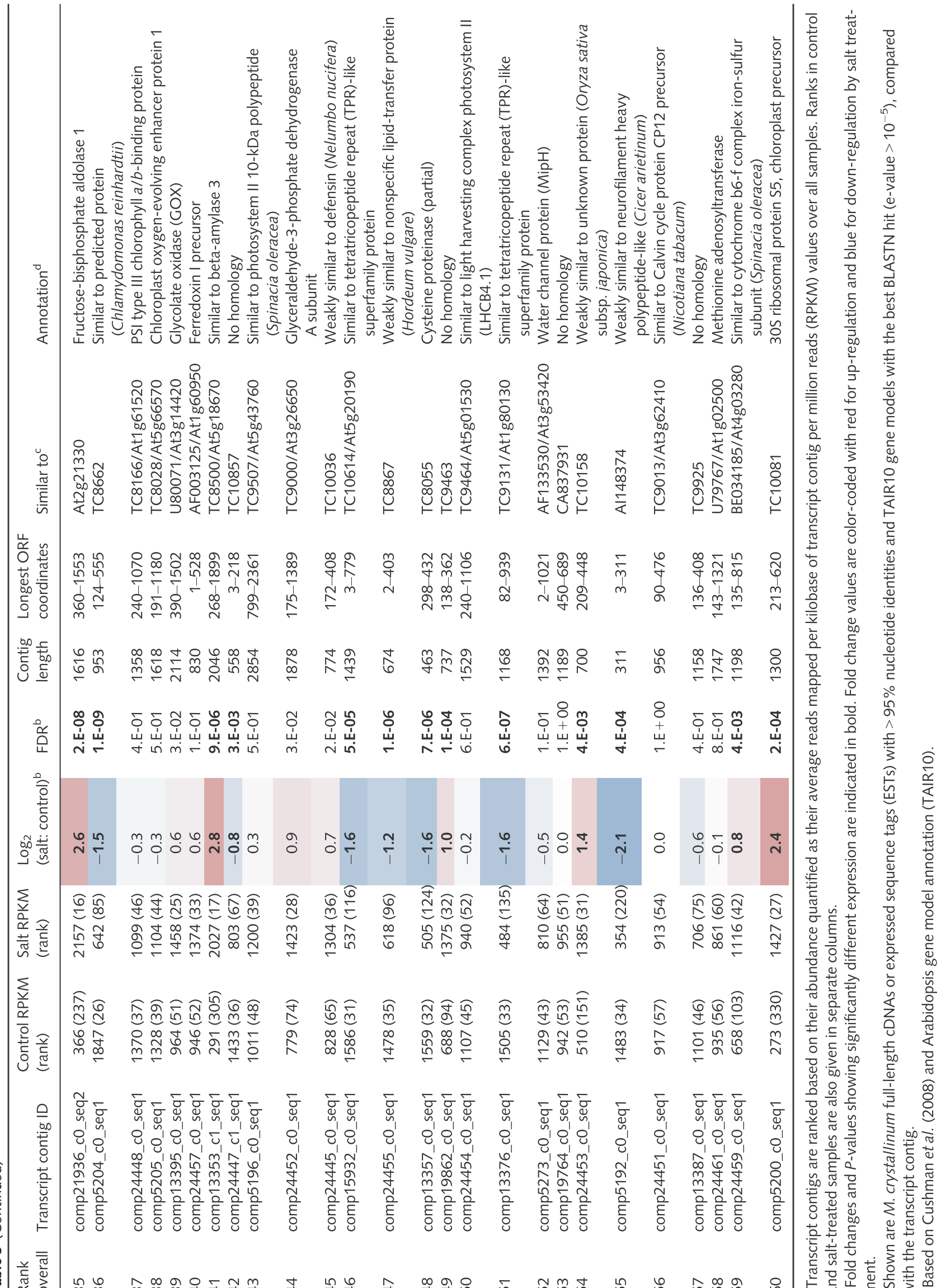

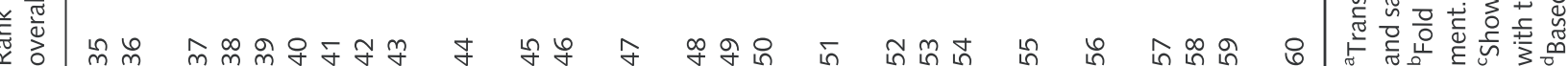




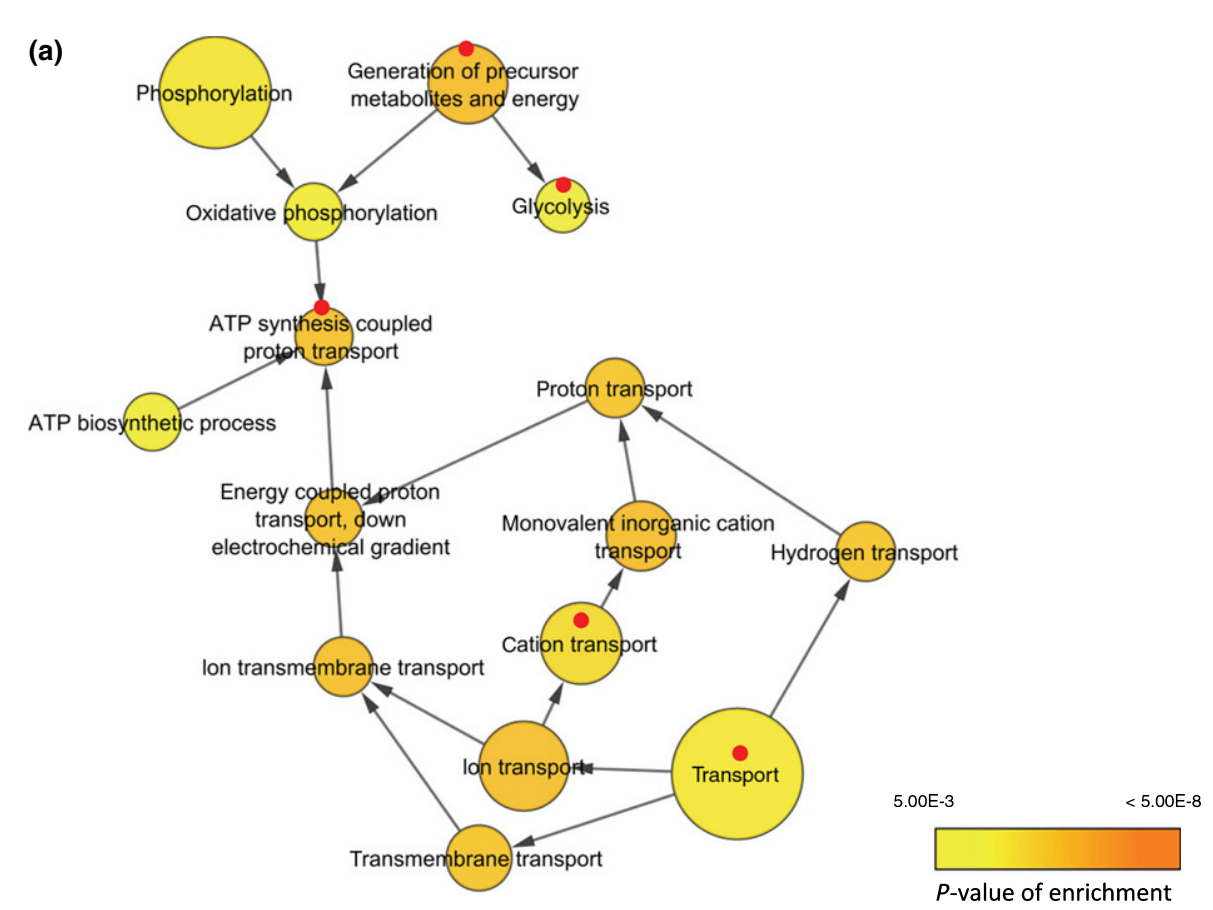

Fig. 4 Examples of networks representing gene ontology (GO) terms enriched among differently expressed transcript contigs (DETs) that are (a) up- or (b) down-regulated by salt treatment in the

Mesembryanthemum crystallinum epidermal bladder cell (EBC) transcriptome. Enriched $\mathrm{GO}$ terms were identified using BINGO and visualized with Cytoscape, as described in the Materials and Methods section. GO terms are connected based on their ancestor-child relationships. Colors of circles indicate the $P$ value of enrichment. Sizes of circles represent the size of GO terms in the background TAIR10 annotation. GO terms selected for the summary in Table 4 are marked with (a) red and (b) blue dots. The complete networks and list of enriched GO terms are presented in Supporting Information Figs S3 and S4, and Table S3, respectively.

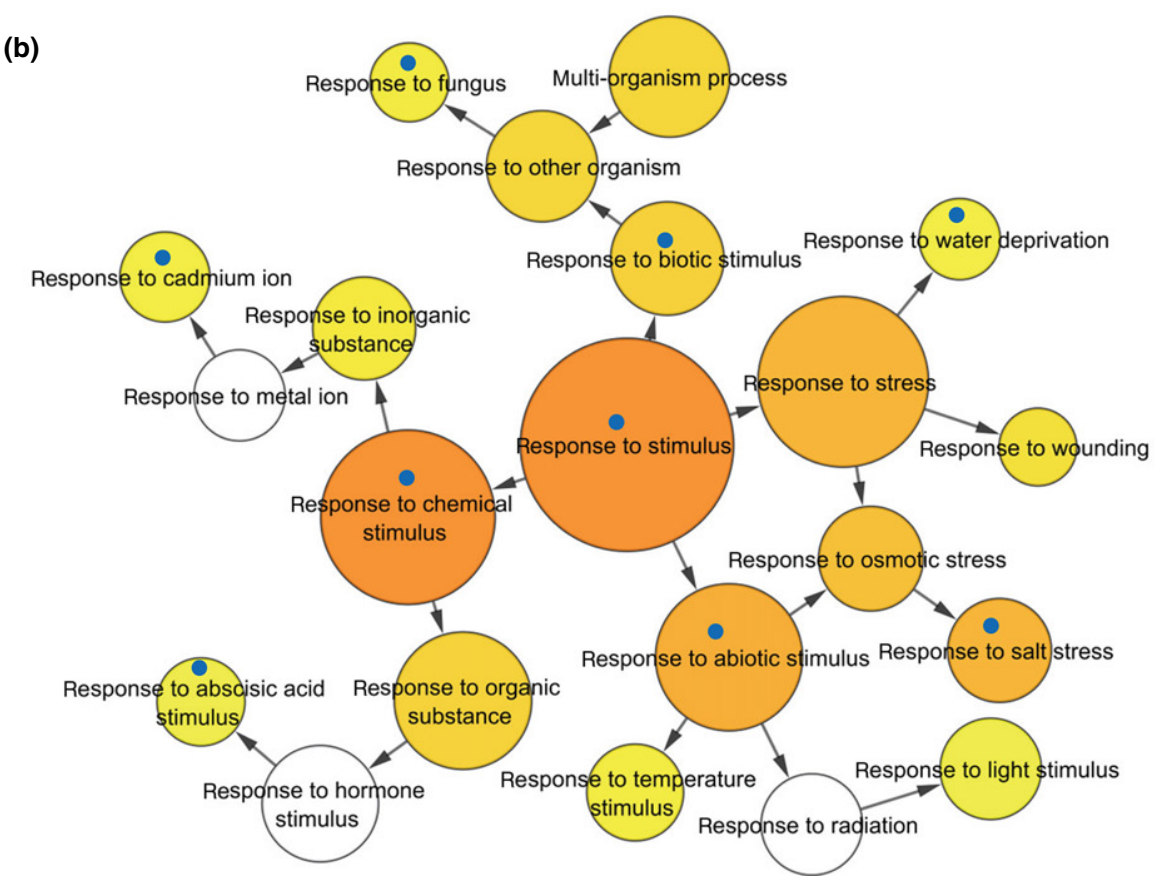

Metabolism Transcript contigs encoding enzymes in hexose catabolism including glycolysis, myo-inositol metabolism, CAM, and proline biosynthesis pathways were all up-regulated by salt (Fig. 5b; Table S4). At least two copies of $\mathrm{Na}^{+} /$myo-inositol transporters, assembled as full-length transcripts, were also salt-induced, by 1.9- and 4-fold, respectively (Table S4). Genes encoding CAM-related enzymes, for example, pyruvate phosphate dikinase (PPDK), phosphoenolpyruvate carboxylase (PEPC), malic enzyme (ME) and malate dehydrogenase $(\mathrm{MDH})$, showed up-regulation by salt (Table S4). In addition, genes involved in the regulation or activation of the enzymes 
Table 4 Summary of gene ontology (GO) biological process (BP) and cellular components (CC) terms enriched in differently expressed transcript contigs (DETs) in the Mesembryanthemum crystallinum epidermal bladder cell (McEBC) transcriptome

\begin{tabular}{|c|c|c|c|c|c|c|}
\hline Salt response & Network $^{\mathrm{a}}$ & GO terms ${ }^{b}$ & $\begin{array}{l}\text { Number } \\
(\%) \text { in DETs }\end{array}$ & $\begin{array}{l}\text { Number }(\%) \text { in } \\
\text { background }^{\mathrm{c}}\end{array}$ & $\begin{array}{l}\log \\
\left(P \text {-value }{ }^{d}\right)\end{array}$ & Representative genes or gene families ${ }^{e}$ \\
\hline \multirow[t]{15}{*}{ Up } & \multirow[t]{4}{*}{ BP-U1 } & Response to stimulus & $225(19.9)$ & $3207(11.6)$ & -13.6 & \\
\hline & & -Response to abiotic stimulus & $101(8.9)$ & $1168(4.2)$ & -9.9 & CA1, CBL10, CIPK3, OZS1 \\
\hline & & -Response to radiation & $44(3.9)$ & $471(1.7)$ & -4.8 & ELIP, IM, INPS, STO \\
\hline & & -Response to hormone stimulus & $56(5.0)$ & $767(2.8)$ & -3.3 & $\begin{array}{l}\text { CNI1, GH3,1, GH3.3, Gibberellin-regulated } \\
\text { family, MPK11, SAUR-like family }\end{array}$ \\
\hline & \multirow[t]{6}{*}{ BP-U2 } & Small molecule metabolic process & $103(9.1)$ & $1248(4.5)$ & -9.0 & \\
\hline & & -Carboxylic acid metabolic process & $50(4.4)$ & $620(2.2)$ & -3.9 & ACO, P5CS2, VTC2 \\
\hline & & -Fatty acid biosynthetic process & $17(1.5)$ & $105(0.4)$ & -4.4 & CER1, FAD8 \\
\hline & & -Hexose catabolic process & $10(0.9)$ & $63(0.2)$ & -2.4 & $F B A 1, H X K 1$, enzymes of glycolysis \\
\hline & & -Flavonoid biosynthetic process & $9(0.8)$ & $46(0.2)$ & -2.8 & McIMT1 \\
\hline & & -Starch biosynthetic process & $5(0.4)$ & $15(0.1)$ & -2.4 & SBPase \\
\hline & \multirow[t]{5}{*}{ BP-U3 } & Transport & $94(8.3)$ & $1502(5.4)$ & -3.2 & $\begin{array}{l}\text { Amino acid transporter family, BAC2, } \\
\text { CAT2, CLC-B, NRT1.1/1.5, SAD2, } \\
\text { SULTR4;1 }\end{array}$ \\
\hline & & -Cation transport & $28(2.5)$ & $271(1.0)$ & -3.7 & NHD1, CHX19, VHA subunits \\
\hline & & $\begin{array}{l}\text { Generation of precursor } \\
\text { metabolites and energy }\end{array}$ & $26(2.3)$ & $199(0.7)$ & -5.1 & PETC, PGRL1B \\
\hline & & $\begin{array}{l}\text {-ATP synthesis coupled } \\
\text { proton transport }\end{array}$ & $10(0.9)$ & $33(0.1)$ & -4.8 & VHA subunits \\
\hline & & -Glycolysis & $8(0.7)$ & $40(0.1)$ & -2.5 & Enzymes of glycolysis \\
\hline \multirow[t]{12}{*}{ Down } & \multirow[t]{6}{*}{ BP-D1 } & Response to stimulus & $265(17.1)$ & $3207(11.6)$ & -8.3 & \\
\hline & & -Response to abiotic stimulus & $113(7.3)$ & $1168(4.2)$ & -5.9 & \\
\hline & & -Response to salt stress & $48(3.1)$ & $360(1.3)$ & -5.6 & $\begin{array}{l}\text { AOC3, BGLU22, CIPK6, HKT1, HOS2, } \\
\text { NCED3, RD19, RD22, SNRK2.7 }\end{array}$ \\
\hline & & -Response to water deprivation & $25(1.6)$ & $188(0.7)$ & -2.7 & $A B A 2, H I S 1-3, N A C 3$, SIP1 \\
\hline & & -Response to biotic stimulus & $60(3.9)$ & $550(2.0)$ & -4.3 & CRK4/5/20, EDS1, WRKY17/23/40/53 \\
\hline & & -Response to fungus & $23(1.5)$ & $156(0.6)$ & -3.0 & ANAC081, BAG6, GSTF7, PR5K, TRX5 \\
\hline & \multirow[t]{4}{*}{ BP-D2 } & Small molecule metabolic process & $125(8.1)$ & $1248(4.5)$ & -7.5 & \\
\hline & & -Carboxylic acid metabolic process & $75(4.8)$ & $620(2.2)$ & -7.4 & ABA4, JAR1, KCS1/9, NAS3, PLD \\
\hline & & $\begin{array}{l}\text {-Cellular amino acid } \\
\text { biosynthetic process }\end{array}$ & $24(1.5)$ & $142(0.5)$ & -4.1 & $\begin{array}{l}\text { CAD4, DHS2, IMS1, MTO3, PGDH, } \\
\text { trpB-containing family }\end{array}$ \\
\hline & & -Vitamin metabolic process & $14(0.9)$ & $63(0.2)$ & -3.4 & QS, THI1 \\
\hline & \multirow[t]{2}{*}{ BP-D3 } & Transport & $122(7.9)$ & $1502(5.4)$ & -3.0 & $\begin{array}{l}\text { AKT1, BAT2, ENT3, GONST4/5, HMTD, } \\
\text { HKT1, NIP4;1, PILS7, PTR1, Sec14p-like }\end{array}$ \\
\hline & & -Anion transport & $13(0.8)$ & $67(0.2)$ & -2.6 & $\begin{array}{l}\text { AAP6, BOR2, NAP3, PHT1;7, NRT1;6, } \\
\text { SULTR3;5 }\end{array}$ \\
\hline \multirow[t]{5}{*}{ Up } & \multirow[t]{3}{*}{ CC-U1 } & Plastid & $196(17.3)$ & $2139(7.8)$ & -23.8 & AIM1, DPE1, GLDP1, LDA, STR16 \\
\hline & & -Plastid stroma & $48(4.2)$ & $354(1.3)$ & -10.4 & $\begin{array}{l}\text { AGT1, CA1, CP33, HCF136, PGM, PRXQ, } \\
\text { RH3, ROC4 }\end{array}$ \\
\hline & & -Plastid thylakoid & $32(2.8)$ & $254(0.9)$ & -6.0 & FBKF13/16-2, NDH18, PSB27, PPL1/2 \\
\hline & \multirow[t]{2}{*}{ CC-U2 } & Vacuole & $53(4.7)$ & $455(1.6)$ & -9.0 & CAS1, Major facilitator family, $P A P 3 / 26$ \\
\hline & & -Vacuolar membrane & $13(1.1)$ & $77(0.3)$ & -3.5 & CAT2, MCITR3, VHA subunits \\
\hline \multirow[t]{6}{*}{ Down } & \multirow[t]{2}{*}{ CC-D1 } & Plastid & $159(10.3)$ & $2139(7.8)$ & -2.4 & ERD9, FD3, NIR1, QS, TPR-like, SIP1 \\
\hline & & _Plastoglobule & $12(0.8)$ & $55(0.2)$ & -2.8 & CCD4, LHC components \\
\hline & \multirow[t]{4}{*}{ CC-D2 } & Endoplasmic reticulum & $43(2.8)$ & $329(1.2)$ & -4.7 & Chaperones, PDI-like \\
\hline & & Golgi apparatus & $35(2.3)$ & $194(0.7)$ & -7.0 & $\begin{array}{l}\text { ERD } 2 B, \text { GAUT1/3/9, GONST4/5, } \\
\text { SAM family }\end{array}$ \\
\hline & & Plant-type cell wall & 29 (1.9) & $180(0.7)$ & -4.6 & EXL2/3, PAP10/12, PDLP1, SCPL46 \\
\hline & & Tubulin complex & $6(0.4)$ & $13(0.0)$ & -2.8 & TUA2, TUB $4 / 7 / 9$ \\
\hline
\end{tabular}

${ }^{\mathrm{a}}$ The entire networks described here are presented as Figs S2 and S3 in the Supporting Information.

${ }^{\mathrm{b}} \mathrm{GO}$ terms best describing all branches of the network are selected.

${ }^{\mathrm{C}} \mathrm{GO}$ annotation of Arabidopsis thaliana (TAIR10, $n=28352$ ).

${ }^{\mathrm{d}}$ Hypergeometric test for enrichment, after Benjamini \& Hochberg False Discovery Rate (FDR) correction.

e Unless otherwise specified, the name of the closest Arabidopsis homolog (TAIR10) is shown. The full list of gene abbreviations is given in Table S7 in the Supporting Information. 
(a)

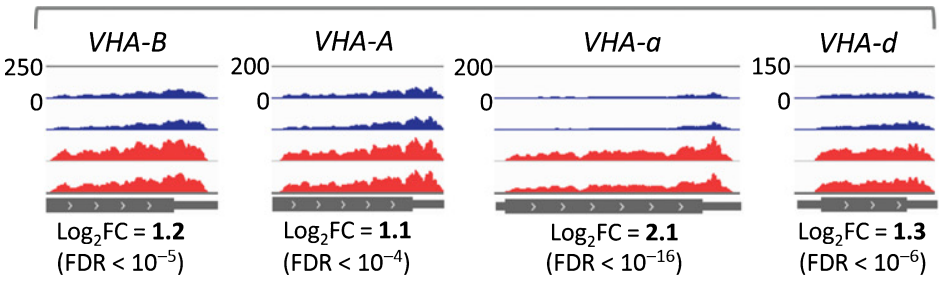

$\mathrm{Na}^{+} / \mathrm{K}^{+}$transporters

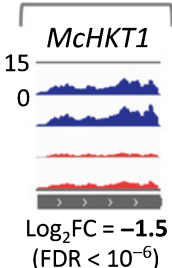

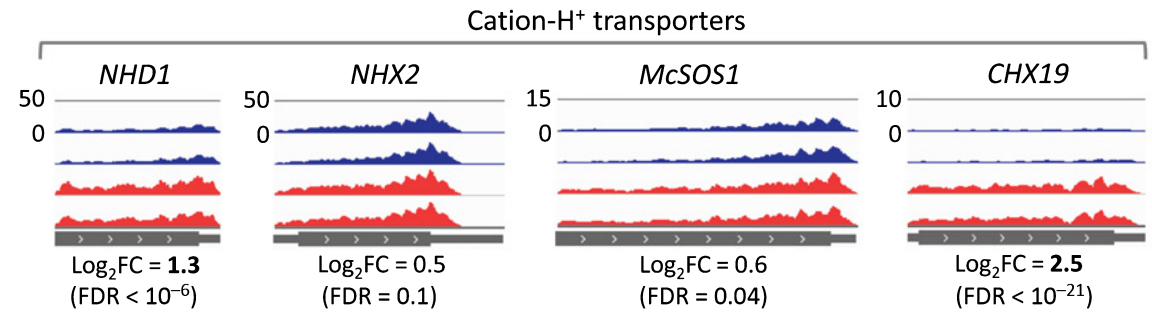

(b)

Myo-inositol metabolism and transport
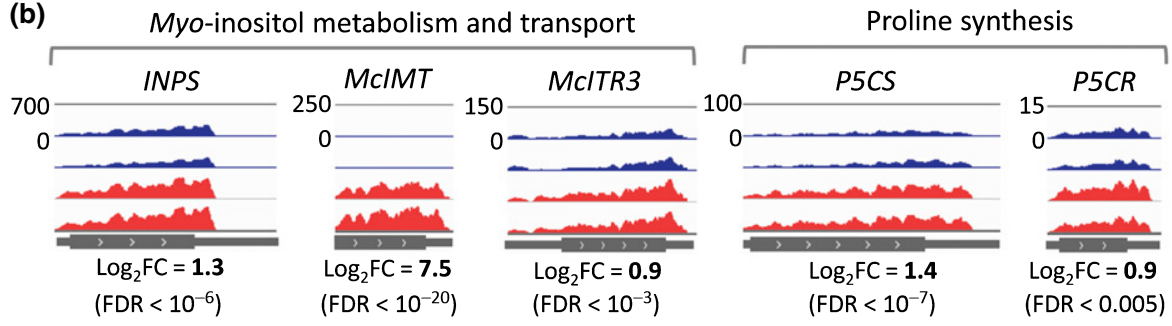

Glycolysis/hexose catabolism

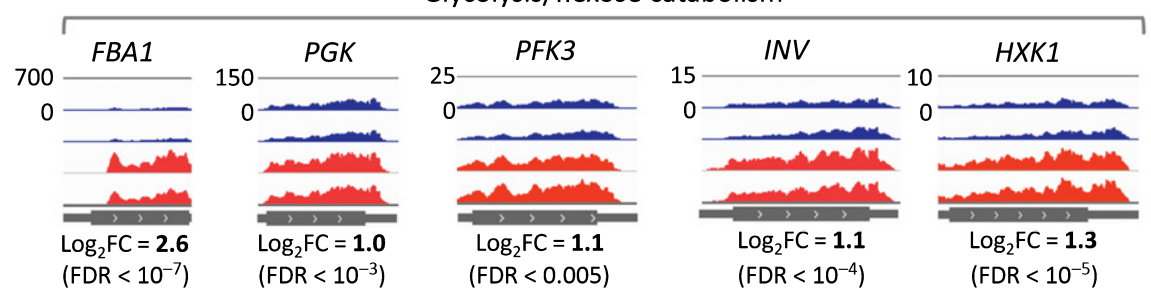

Salt response of Mesembryanthemum crystallinum transcripts involved in (a) $\mathrm{Na}^{+}$ ion transport and (b) metabolic pathways for osmolyte accumulation. Histograms indicate the counts of uniquely mapped RNA-seq reads per million total reads (RPM), of control (blue) and salt-treated (red) samples. The range of RPM, indicated on the $y$-axis of the uppermost histogram, is for all four histograms. Gray bars below the histograms signify the transcript with the deduced open reading frame (ORF) shown as thicker boxes. ' $\log _{2} \mathrm{FC}$ ' is the log value of fold change (FC) produced by salt treatment, with statistically significant differences (false discovery rate $($ FDR $)<0.01)$ indicated in bold.

Crassulacean acid metabolism (CAM)

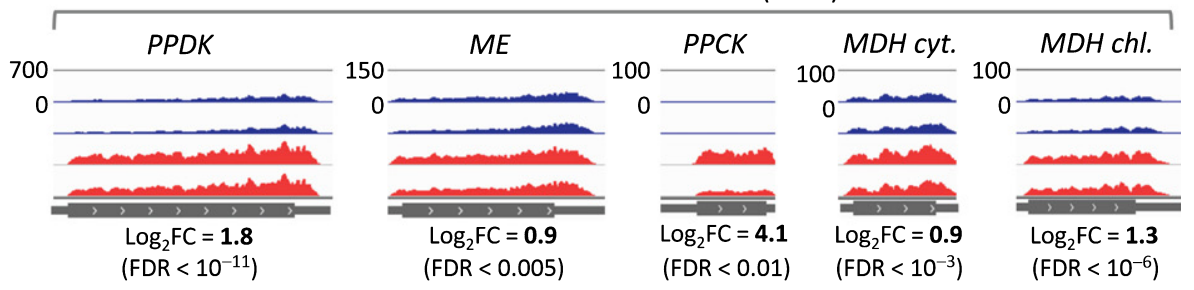

5'UTR ORF 3'UTR

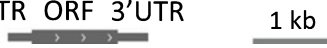

in the CAM cycle, such as PPDK kinase and PEPC kinase, were induced by 3.5 - and 17 -fold, respectively, upon salt treatment. Transcripts encoding two key enzymes in proline biosynthesis, a delta 1-pyrroline-5-carboxylate synthase (McP5CS; AF067967) and a homolog of pyrroline-5- carboxylate reductase (P5CR), also showed 2.6- and 1.8-fold higher expression, respectively, in salt-treated samples (Fig. 5b; Table S4).

Stress signalling Transcripts homologous to genes canonically identified as stress-responsive in Arabidopsis and other nonhalophyte species were either unchanged or down-regulated by salt in EBCs. Homologs of genes involved in ABA synthesis and stress signalling, such as ABA DEFICIENT 1 (ABA1), ABA3, ABA INSENSITIVE 1 (ABII), ABI5, ABA RESPONSIVE ELEMENT-BINDING FACTOR 3 (ABF3) and ABI5 BINDING PROTEIN 1 (AFPI), were not significantly affected (i.e. FDR $>0.01$; Table S1). Other genes in this category were downregulated by salt, for example: ABA2, NINE-CISEPOXYCAROTENOID DIOXYGENASE 3 (NCED3) and transcription factors listed in the 'ABA signalling' section of Table 
(a) Abscisic acid ( $A B A)$ synthesis and signaling

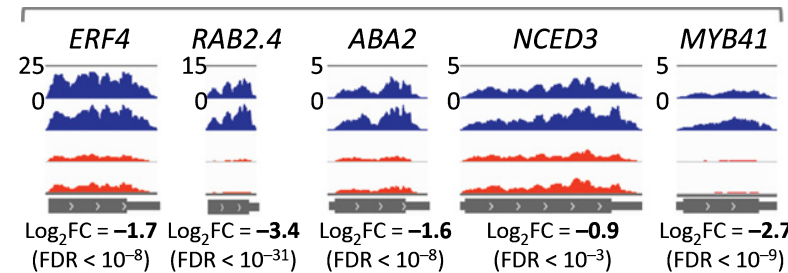

\section{Canonical ABA-induced genes}

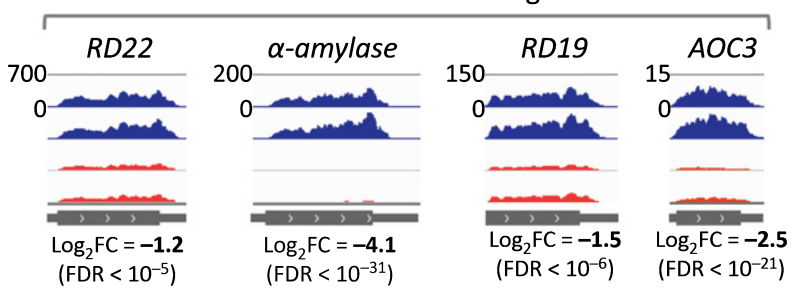

CIPK/CBL pathways

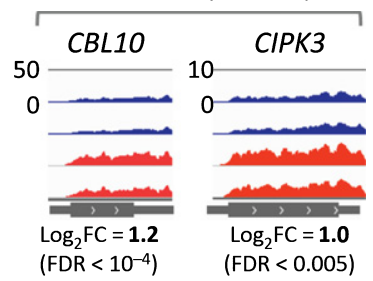

Responsive to radiation

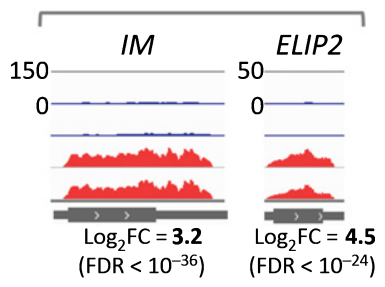

(b) Endoplasmic reticulum (ER) chaperones

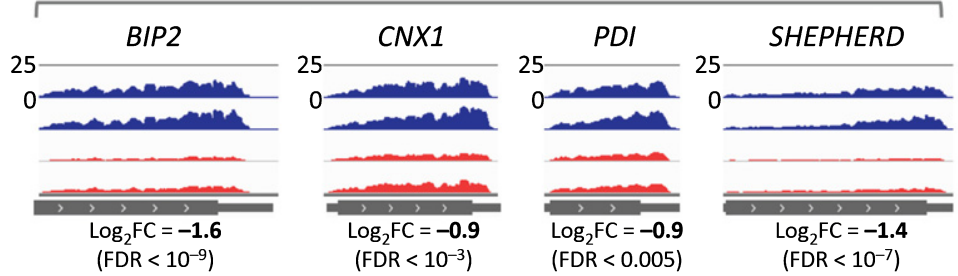

Golgi-targeted proteins

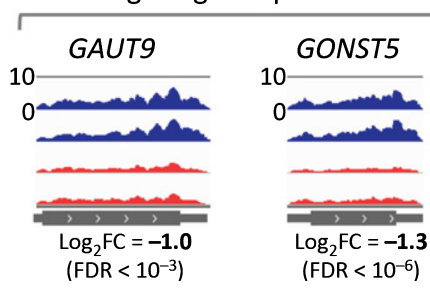

Fig. 6 Salt response of Mesembryanthemum crystallinum transcripts involved in (a) stress signaling and responses, and (b) endoplasmic reticulum (ER) and Golgi functions. Histograms indicate the counts of uniquely mapped RNA-seq reads per million total reads (RPM), of control (blue) and salttreated (red) samples. The range of RPM, indicated on the $y$-axis of the uppermost histogram, is for all four histograms. Gray bars below the histograms signify the transcript with the deduced open reading frame (ORF) shown as thicker boxes. ' $\mathrm{Log}_{2} \mathrm{FC}$ ' is the log value of fold change (FC) produced by salt treatment, with statistically significant differences (false discovery rate $($ FDR $)<0.01)$ indicated in bold.
S6. Likewise, all homologs of the RESPONSIVE TO DESICCATION and RESPONSIVE TO DEHYDRATION $(R D)$ family genes, including an $R D 2$, an $R D 19$, two $R D 28$ and two $R D 22$ homologs, were either unchanged or down-regulated in EBCs by salt (Fig. 6a; Tables S1, S6). Exceptions to this trend include two homologs of CALCINEURIN B-LIKE PROTEIN 10 (CBL10) and a CBL-INTERACTING PROTEIN KINASE 3 (CIPK3) homolog, which showed 2.0- to 5.9-fold increases in response to salt treatment (Table S6). Among the stress-responsive genes, those involved in high light or radiation responses were highly salt-induced in EBCs. For example, expression of an IMMUTANS (IM) homolog and three EARLY LIGHTINDUCIBLE PROTEIN 2 (ELIP2) homologs were induced by 8.6- to 42.2-fold in salt-treated EBC samples (Fig. 6a; Table S1).

Organelle functions Among genes involved in organelle functions, one of the most conspicuous changes upon salt treatment in EBCs was the down-regulation of almost all transcript contigs involved in protein folding and modification, and localized to the endoplasmic reticulum (ER) and Golgi apparatus, as shown in Table S7. Among the 442 EBC transcript contigs annotated with the GO terms 'endoplasmic reticulum' or 'Golgi apparatus', 90 contigs (c. 20\%) showed down-regulation, while only $20(4.5 \%)$ were up-regulated by salt (FDR $<0.01)$. Homologs of ER chaperones and protein disulphide isomerase (PDI) family genes showed 1.7- to 3.0-fold lower expression in the salt-treated samples (Fig. 6b; Table S7, 'ER chaperones'). Similarly, transcripts encoding enzymes and transporters targeted to the Golgi apparatus were down-regulated by 1.6 - to 3.0 -fold by salt treatment (Fig. 6b; Table S7, 'Golgi apparatus'). Salt-up-regulated transcripts that encode ER- or Golgi apparatus-targeted proteins included homologs of vesicle transport-related genes (Table S7, 'Vesicle transport in ER and Golgi'), as well as two homologs of Arabidopsis ECERIFERUM 1 (CERI) (Table S1).

\section{Discussion}

We constructed a cell-type-specific transcriptome for EBCs by de novo assembly, and characterized the transcriptome response of this single cell type to salt stress. To facilitate quantification of the transcript abundance based on nonambiguously mapped RNA-seq reads, we aimed to assemble a reference transcriptome 
with minimum possible sequence redundancy and misassembled chimeras. Based on comparisons of multiple assemblers (data not shown; Yang \& Smith, 2013), we chose the Trinity assembler and a custom filtering pipeline to create the nonredundant EBC transcriptome.

The quantification of expression highlighted biological processes that are enriched in EBCs, as well as their cell type-specific salt regulation. For example, a homolog of GLABRA 2 (GL2), a transcription factor required for trichome development in Arabidopsis (Rerie et al., 1994), was up-regulated by salt (5.8fold; FDR $<10^{-21}$ ) in EBCs (Table S1), mirroring the development process of EBCs from trichome initiating cells (Adams et al., 1998). This approach also captured transcripts encoding proteins that had been previously found to be highly abundant in the EBC-specific proteome (Jou et al., 2007; Barkla et al., 2012). Examples include homologs for all VHA subunits, which were among the top 2\% most abundant EBC transcripts (Tables S1, S4), as well as a RUBISCO small subunit, and cysteine protease genes (ranks 6 and 8 in Table 3). We also compared the composition of McEBC transcripts with published leaf/shoot transcriptomes, to highlight the cell specificity (Tables S8, S9).

\section{Sodium and water transport captured in the McEBC transcriptome}

The $\mathrm{Na}^{+}$sequestration in EBC vacuoles appears to be a critical component of salt stress adaptation in $M$. crystallinum, given that EBCs represent up to $25 \%$ of the aboveground volume of the plants (Lüttge etal., 1978; Barkla etal., 2002). Vacuolar $\mathrm{Na}^{+}$ deposition requires energy, probably provided by vacuolar proton pumps, which is supported by the increase in activity and abundance of the VHA proteins in salt-treated M. crystallinum epidermal leaf tissue peels (Barkla et al., 1995, 2009). Our data also support this view by showing higher expression of transcripts encoding all of the VHA subunits in EBCs from salt-treated plants (Fig. 7; Table S4).

The EBC PM has been reported to have a high conductivity to both water and salt (Steudle et al., 1975). However, salt-induced transcriptional activation of known $\mathrm{PM} \mathrm{Na}^{+}$transporters was not significant in our study. While the EBC transcriptome captured homologs of transporters suggested to function in low-affinity $\mathrm{Na}^{+}$entry into plant cells, such as HKT1 (Benito et al., 2014; Maathuis, 2014), including near full-length copies of the previously known McHKT1 and McHKT2 (Su et al., 2003) and a third novel HKT1 homolog, these all showed decreased expression in EBCs from salt-treated plants (Fig. 7; Tables S1, S4). One explanation is the presence of still unknown components of the cellular $\mathrm{Na}^{+}$uptake pathways, such as the nonselective cation channels that have been identified at the PM of root cells (Demidchik \& Tester, 2002). Another explanation would be to assume posttranslational mechanisms rather than transcription or transcript stabilization are collectively responsible for the regulation of flux required to deposit $\mathrm{Na}^{+}$into the cell.

The sequestration of $\mathrm{Na}^{+}$into vacuoles is thought to be mediated by $\mathrm{Na}^{+}-\mathrm{H}^{+}$exchangers. EBC tonoplast $\mathrm{Na}^{+}-\mathrm{H}^{+}$exchange activity is induced by salt and significantly higher than that measured in leaf mesophyll cells (Barkla et al., 2002). Members of the monovalent Cation: Proton Antiporter 1 (CPA1)-like transporters include tonoplast $\mathrm{Na}^{+}-\mathrm{H}^{+}$or $\mathrm{K}^{+}-\mathrm{H}^{+}$exchangers (Bassil et al., 2011; Barragán et al., 2012). Multiple transcripts homologous to AtNHX2, AtNHX4 and AtNHXG were captured as full-length transcripts in the McEBC transcriptome. Among them, the NHX2 homolog showed the highest basal expression level (Table S4), ranked within the top $2 \%$ most abundant (Table S1). However, none of the NHX family homologs showed significant induction in response to salt treatment (Tables $S 1$, S4). Other possible candidates for vacuole $\mathrm{Na}^{+}$uptake are members of the CPA2-like transporter family, which have been implicated in salt tolerance (Qi et al., 2014). One member of this family, a homolog of $A t C H X 19$, localized to the prevacuolar compartment and late endosomes (Chanroj et al., 2011), showed transcript levels increased by 5.7 -fold in salt-treated samples (Fig. 7; Table S4).

Prevention of passive leakage of $\mathrm{Na}^{+}$back into the cytosol is another critical aspect of vacuolar $\mathrm{Na}^{+}$sequestration, minimizing futile $\mathrm{Na}^{+}$cycling between the cytosol and vacuole. The fast vacuolar (FV) and slow vacuolar (SV) tonoplast channels show nonselective monovalent cation permeability and thus mediate $\mathrm{Na}^{+}$ transport between the cytosol and vacuole in both halophytes and glycophytes (Pantoja et al., 1989; Bonales-Alatorre et al., 2013a; Shabala, 2013). A recent study illustrated that the negative regulation of SV and FV tonoplast channels reduced $\mathrm{Na}^{+}$leak, to establish successful $\mathrm{Na}^{+}$sequestration in vacuoles and confer salt tolerance in the halophytic crop quinoa (Chenopodium quinoa) (Bonales-Alatorre et al., 2013b). While the transcript identity of FV channels remains unknown, the TWO-PORE CHANNEL 1 (TPC1) gene is known to encode an SV channel (Peiter et al., 2005; Hedrich \& Marten, 2011). Our results show a 3.3-fold repression of a TPC1 homolog by salt in EBCs (Fig. 7; Table S10).

McNHD1, an $\mathrm{Na}^{+}-\mathrm{H}^{+}$exchanger localized to the chloroplast envelope, was transcriptionally up-regulated in EBCs by salt (Fig. 5a). NHD1 protects the photosynthetic machinery from toxic concentrations of $\mathrm{Na}^{+}$, by maintaining a low $\mathrm{Na}^{+}$concentration in the stroma (Müller et al., 2014). In addition to ion transporters, there has been speculation that $\mathrm{Na}^{+}$transport could be mediated through vesicular trafficking between the PM, prevacuolar compartments, and the vacuole (MacRobbie, 1999; Garcia de la Garma et al., 2014). In the EBCs, a relatively large number of transcript contigs showing altered expression in response to salt were observed among genes associated with vesicle trafficking (Fig. 7, Vesicle/Endosome).

The transmembrane movement of water is facilitated by channels of the major intrinsic protein (MIP) family in plants (Kirch et al., 2000; Quigley et al., 2002). Among 28 MIP transcripts in the McEBC transcriptome, the PM intrinsic protein (PIP) subfamily was the most abundant (e.g. rank 52 in Table 3). Five out of a total number of 11 PIP subfamily members ranked within the top $2 \%$ most abundant transcripts. None of the PIP homologs showed significantly altered expression after salt stress, except for a PIP1;5 homolog, which was significantly down-regulated by 2.7 fold (FDR $<10^{-7}$; Fig. 7; Table S1). Expression differences by salt 


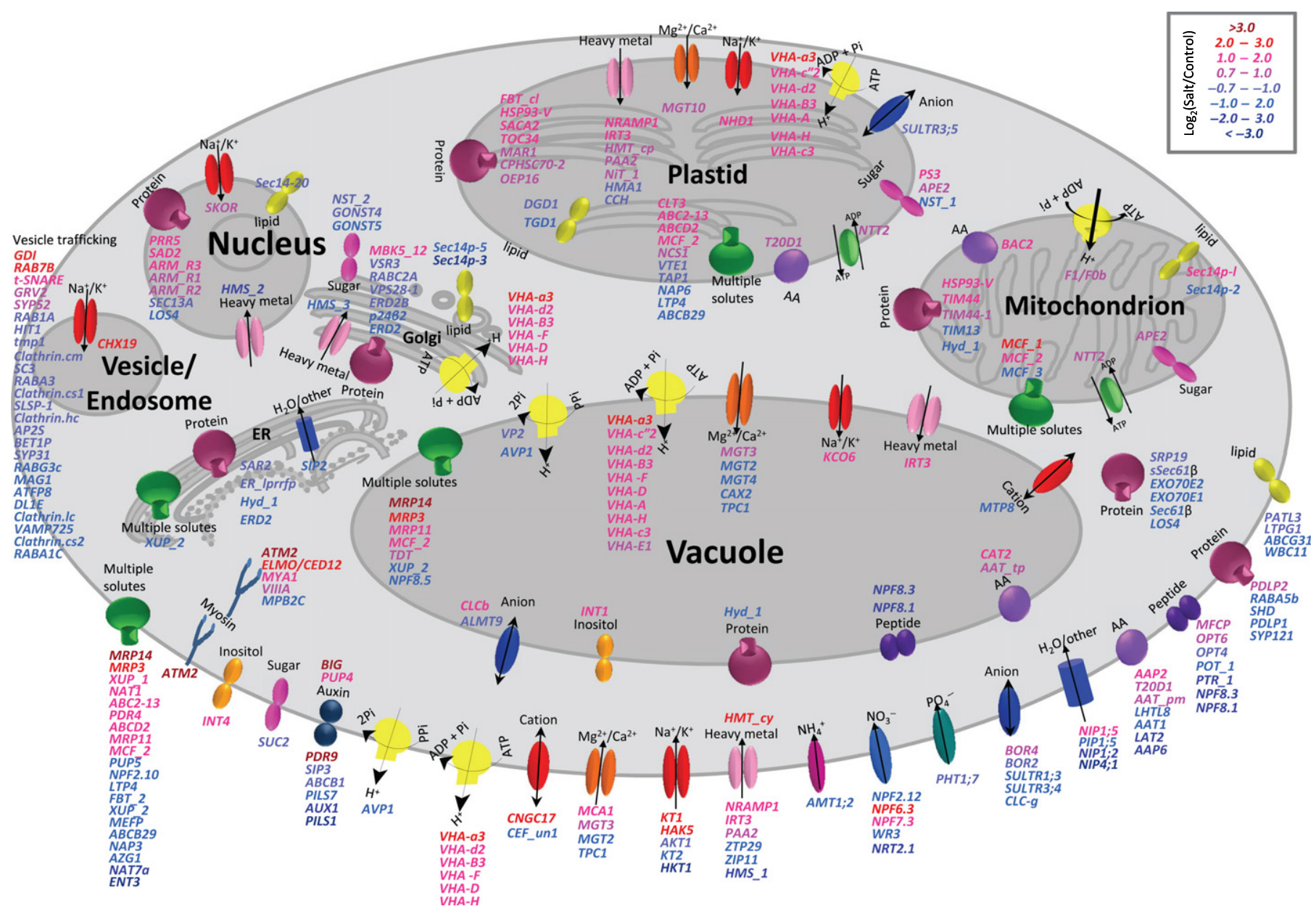

Fig. 7 Transcripts with significantly altered expression between control and salt-treated epidermal bladder cells (EBCs) that code for putative transporters in Mesembryanthemum crystallinum are represented with respect to their cellular localization known for Arabidopsis. Transporters are identified with the primary solutes or ions they transport and abbreviated gene model names coding for them. The color of the gene model names represents the log $\mathrm{g}_{2}$ fold change based on reads mapped per kilobase of transcript contig per million reads (RPKM) values between control and salt-treated samples. Gene model names, transcript IDs, annotations, and expression values are listed in Supporting Information Table S10. Transcripts coding for transporters localized to more than one intracellular compartment are represented in multiple cellular locations.

treatment were observed mainly with the less abundant Nodulin26-like protein (NIP) subfamily. A homolog of AtNIP4;1 was significantly down-regulated by 45.3 -fold $\left(\mathrm{FDR}<10^{-53}\right.$ ), while an AtNIP5;1 homolog was the only MIP member observed to be up-regulated, by 2.7 -fold (FDR $=10^{-4}$; Fig. 7; Table S1). Rather than facilitating the movement of water, these proteins have been implicated in the transport of glycerol, silicon, boron, urea and arsenic (Mitani-Ueno et al., 2011). In Arabidopsis, biosynthesis and accumulation of glycerol play an important role in conferring salt tolerance (Bahieldin et al., 2014).

Collectively, a large number of transcripts for diverse membrane transport functions were identified in the McEBC transcriptome and regulated by salt (Fig. 7). The presence of ion channels and transporters, as well as transporters of amino acids, sugars, glutathione, xanthine, xenobiotics, lipids, inositols, water, hormones such as auxin, and other compounds, is fundamental to the McEBC physiology, and their regulation by salinity is key to the understanding of how McEBCs sense and respond to salinity.
RNA-seq suggests that EBCs are active in compatible solute synthesis

Inorganic ions, especially $\mathrm{Na}^{+}$, accumulating in the vacuoles of salt-treated EBCs are balanced by metabolites such as pinitol and proline in the cytosol. Pinitol has been shown to comprise $71 \%$ of the soluble carbohydrate fraction in salt-treated leaves of M. crystallinum, compared with only $5 \%$ in controls (Paul \& Cockburn, 1989). Concentrations of $1 \mathrm{mM}$ proline and $2.2 \mathrm{mM}$ pinitol have been measured in salt-treated EBCs (Adams et al., 1998). Our RNA-seq results suggest salt induction of metabolic pathways that lead to synthesis, accumulation, transport, and conversion to other metabolically active groups contributing to stress management, in EBCs (Figs 5b, 8; Table S5). For example, beta-amylase, invertase and hexokinase participate in starch degradation to provide glucose-6-phosphate that can be converted to myo-inositol, and then to D-pinitol and D-ononitol. These and a variety of other sugar alcohols have been shown to accumulate 


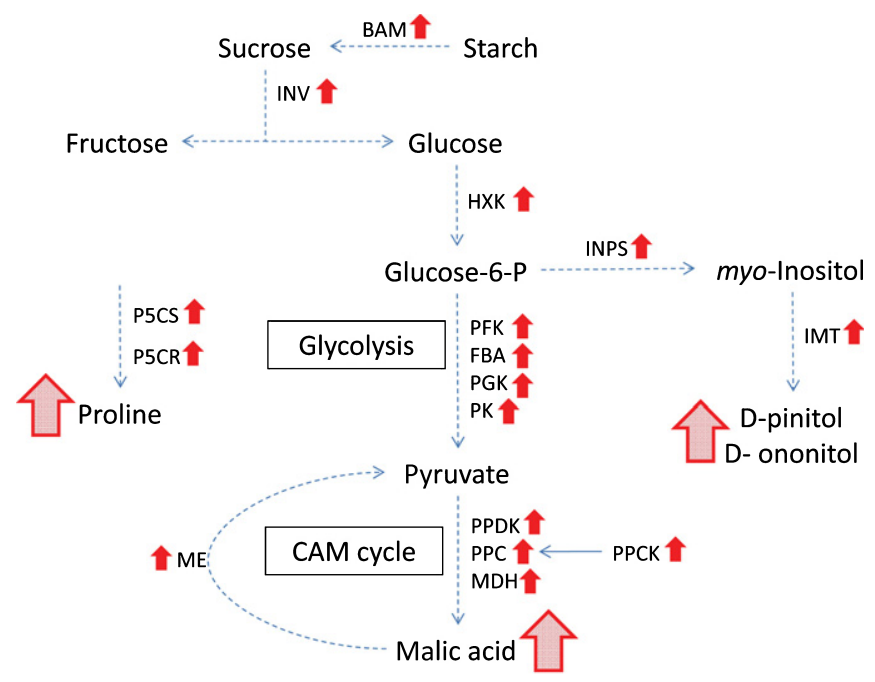

1 : transcript up-regulated (this study)

仓: metabolite known to accumulate in response to salt in $M$. crystallinum

Fig. 8 Metabolic pathways activated in Mesembryanthemum crystallinum epidermal bladder cells (EBCS) by salt, resulting in accumulation of osmoticums. BAM, beta-amylase; INV, invertase; HXK, hexokinase; INPS, myo-inositol-1-phosphate synthase; IMT, inositol methyl transferase; P5CS, delta 1-pyrroline-5-carboxylate synthase; P5CR, pyrroline-5carboxylate reductase; PFK, phosphofructokinase; FBA, fructosebisphosphate aldolase; PGK, phosphoglycerate kinase; PK, pyruvate kinase; PPDK, pyruvate phosphate dikinase; PPC, phosphoenolpyruvate carboxylase; $M D H$, malate dehydrogenase; $M E$, malic enzyme; PPCK, phosphoenolpyruvate carboxylase kinase.

under salt and water stress in many halophytes including M. crystallinum (Flowers \& Colmer, 2008).

The synthesis of myo-inositol, the precursor for the sugar alcohols ononitol and pinitol that accumulate under salt stress (Vernon \& Bohnert, 1992a), is also enhanced by salinity (Ishitani et al., 1996). In EBCs, transcripts encoding myo-inositol-1-phosphate synthase (INPS; Ishitani etal., 1996) and myo-inositol O-methyltransferase 1 (IMT1; Vernon \& Bohnert, 1992a,b), two key enzymes in the pathway leading to D-pinitol via D-ononitol, were highly abundant (ranks 23 and 78, respectively, in Tables 3 and S1), and up-regulated by salt, with the IMT1 transcript exhibiting one of the highest fold changes observed in our study (>170-fold; Table S5). IMT became one of the most abundant transcripts in the salt-treated transcriptome (rank 35), while showing highly suppressed expression in the control samples (rank 10232), suggesting a strict regulatory mechanism by salt in EBCs (Table S1, comp5305_c0_seq1).

Homologs of PM and tonoplast $\mathrm{H}^{+}$or $\mathrm{Na}^{+} /$myo-inositol transporter (ITR) genes, INT1 and INT4, were up-regulated by salt (Fig. 7; Table S10). PM-localized ITRs have been associated with the long-distance $\mathrm{Na}^{+}$transport and vacuolar $\mathrm{Na}^{+}$unloading that lead to the transport of myo-inositol into the cytoplasm, where it serves as a precursor for D-ononitol and D-pinitol (Vernon \& Bohnert, 1992a; Nelson et al., 1999; Chauhan et al., 2000). These polyols may function in scavenging hydroxyl radicals that are not targeted by reactive oxygen species (ROS) scavenging enzymes (Smirnoff \& Cumbes, 1989; Peshev et al., 2013). Interestingly, the most abundant ITR in EBCs was Mitr3 (AY233386; F. Quigley et al., unpublished), while Mitr2, previously known as the leaf-specific paralog (Chauhan et al., 2000), was not detected in the McEBC transcriptome, suggesting cell type-specific transcript compartmentalization (Table S1).

Salt stress initiates a shift from $\mathrm{C}_{3}$ to CAM carbon fixation mode in M. crystallinum (Adams et al., 1998). Proteomic profiling of EBC extracts identified several CAM-specific isoforms of enzymes in these cells, suggesting that EBCs may contribute to the carbon fixation process in the leaf (Barkla et al., 2012). Our RNAseq identified transcripts for multiple essential CAM genes, with many showing significant salt induction (Table S5). These included PEPC kinase, induced by the largest fold difference among CAM-related transcripts at $>16$-fold. PEPC kinase regulates PEPC activity, thus controlling the primary assimilation of $\mathrm{CO}_{2}$ in CAM plants (Taybi et al., 2000). CAM-related transcripts show diurnal fluctuation in their expression, while generally found to have higher basal-level expression in salt-stressed leaf tissues compared with unstressed samples (Cushman etal., 2008). The accumulation of malic acid and other organic acids, and their diurnal fluctuations and physiological role in EBCs, possibly as osmoticums, as observed in some CAM plant species (Herrera, 2009), remain to be elucidated in future studies.

\section{EBC salt stress-responsive gene expression}

EBCs illustrate a salt response centered on the energy-intensive process of $\mathrm{Na}^{+}$and osmolyte accumulation, including the proline synthesis pathway (Table S5), while deprioritizing canonical stress responses. RNA-seq results for EBC samples from salttreated plants indicate that cells are in a stress-adapted state and therefore do not show hallmarks of transcript induction under salt stress as observed for glycophytes (Gong et al., 2005).

Indeed, salt treatment appeared to relieve EBCs of osmotic stress when compared with the control samples, arguably using the accumulated $\mathrm{Na}^{+}$and other compatible solutes as osmoticums (Adams et al., 1998). GO terms enriched in DETs with decreased expression in response to salt treatment include 'response to salt stress', 'response to water deprivation' and 'response to biotic stress' (Fig. 4b; Table 4, BP-D1). These include homologs induced by ABA, salt, and osmotic stresses in Arabidopsis and other glycophytes (Table S5), as well as defenserelated genes. Notably, transcripts encoding homologs of RD or early response to dehydration (ERD) family proteins showed down-regulation by salt in EBCs (Fig. 6a; Tables S1, S5).

In contrast, we observed salt induction of transcripts that provide protection from certain abiotic stresses, for example, transcripts in the GO term 'response to radiation' (Table 4, BP-U1; Fig. S3a). Furthermore, transcripts encoding homologs of CBL and CIPK family proteins showed increased expression upon salt treatment. Two copies of CBL10 homologs were identified in the EBC transcriptome. Both showed up-regulation in response to salt. CBL10, often found duplicated in salt-adapted species (Oh etal., 2014; Tang etal., 2014), functions as a calcium sensor together with CIPK24 to regulate $\mathrm{Na}^{+}$transport at the tonoplast (Kim etal., 2007), and as a regulator of PM K $\mathrm{K}^{+}$transport by 
modulating AKT1 activity via a direct interaction (Ren et al., 2013), in Arabidopsis. These dual roles of CBL10 may facilitate both $\mathrm{K}^{+}$uptake and $\mathrm{Na}^{+}$sequestration in the cell, coordinating $\mathrm{K}^{+}: \mathrm{Na}^{+}$ratios in the cytoplasm. CBL10 is also involved in anthocyanin accumulation in Arabidopsis, as a response to UV irradiation (Quan et al., 2007; Heyndrickx \& Vandepoele, 2012). When plants are exposed to prolonged stress, McEBCs accumulate betacyanins and betaxanthins (Figs 1d, 2b, S1), which provide protection from strong irradiation (Vogt et al., 1999). Supporting this finding, a transcript contig encoding a 4,5-DOPA-extradiol dioxygenase, a key enzyme in the biosynthesis of the precursor of betacyanins and betaxanthin (Harris et al., 2012), showed a three-fold increase in expression in response to salt (Table S1, comp28325_c0_seq1).

Finally, our RNA-seq study revealed the gene regulation associated with the massive intracellular functional reorganization within EBCs upon salt treatment. This included concerted down-regulation of genes involved in ER and Golgi functions, as well as cell wall components (Table 4, CC-D2; Table S7). However, transcripts linked to the GO term 'vacuole' remained upregulated in the salt-treated samples, suggesting the continued importance of vacuoles in stress-regulated EBCs (Table 4, CCU2; Table S7).

\section{Conclusions}

The McEBC transcriptome carries a unique profile that represents cell type-specific roles in the whole-plant integrated stress adaptation mechanisms. Transcripts associated with most of the signature pathways for salinity or water stress were down-regulated in the salt-adapted EBCs compared with EBCs from control plants. However, transcripts in pathways critical for metabolically active cellular functions under prolonged salt stress and pathways involved in protection against radiation were upregulated. Our results support the notion of EBCs as metabolically active cells with unique stress responses.

About $32 \%$ of transcripts showing significant salt regulation in EBCs contained no sequence similarity (based on BLASTN $\mathrm{e}<10^{-5}$ ) to reference RNA sequences from any other plant species and were therefore functionally uncharacterized. These potentially lineage-specific transcripts may make important contributions to the development of the unique cell types and, in turn, the whole-plant salt-adaptation capacity of M. crystallinum. Our research demonstrates the utility of cell type-specific approaches, and provides resources for future investigations of the genetic mechanism of EBC functions.

\section{Acknowledgements}

This work was supported by the Next-Generation BioGreen21 Program (grant no. PJ011379) of the Rural Development Administration, Republic of Korea, LSU Biological Sciences Departmental funds awarded to M.D. The authors thank High Performance Computing at the Louisiana State University (HPC@LSU) for assistance with computer resources, Keck Center staff at the University of Illinois for sequencing, and Guannan
Wang and Lauren Taylor for their help during preparation of the manuscript.

\section{References}

Adams P, Nelson DE, Yamada S, Chmara W, Jensen RG, Bohnert HJ, Griffiths H. 1998. Growth and development of Mesembryanthemum crystallinum (Aizoaceae). New Phytologist 138: 171-190.

Adams P, Thomas JC, Vernon DM, Bohnert HJ, Jensen RG. 1992. Distinct cellular and organismic responses to salt stress. Plant and Cell Physiology 33: $1215-1223$.

Agarie S, Shimoda T, Shimizu Y, Baumann K, Sunagawa H, Kondo A, Ueno O, Nakahara T, Nose A, Cushman JC. 2007. Salt tolerance, salt accumulation, and ionic homeostasis in an epidermal bladder-cell-less mutant of the common ice plant Mesembryanthemum crystallinum. Journal of Experimental Botany 58: 1957-1967.

Anders S, Huber W. 2010. Differential expression analysis for sequence count data. Genome Biology 11: R106.

Bahieldin A, Sabir JSM, Ramadan A, Alzohairy AM, Younis RA, Shokry AM, Gadalla NO, Edris S, Hassan SM, Al-Kordy MA et al. 2014. Control of glycerol biosynthesis under high salt stress in Arabidopsis. Functional Plant Biology 41: 87.

Bailey-Serres J. 2013. Microgenomics: genome-scale, cell-specific monitoring of multiple gene regulation tiers. Annual Review of Plant Biology 64: 293-325.

Barkla BJ, Castellanos-Cervantes T, de León JLD, Matros A, Mock H-P, PerezAlfocea F, Salekdeh GH, Witzel K, Zörb C. 2013. Elucidation of salt stress defense and tolerance mechanisms of crop plants using proteomics - current achievements and perspectives. Proteomics 13: 1885-1900.

Barkla BJ, Vera-Estrella R, Camacho-Emiterio J, Pantoja O. 2002. $\mathrm{Na}^{+} / \mathrm{H}^{+}$ exchange in the halophyte Mesembryanthemum crystallinum is associated with cellular sites of $\mathrm{Na}^{+}$storage. Functional Plant Biology 29: 1017-1024.

Barkla BJ, Vera-Estrella R, Hernández-Coronado M, Pantoja O. 2009. Quantitative proteomics of the tonoplast reveals a role for glycolytic enzymes in salt tolerance. Plant Cell 21: 4044-4058.

Barkla BJ, Vera-Estrella R, Pantoja O. 2012. Protein profiling of epidermal bladder cells from the halophyte Mesembryanthemum crystallinum. Proteomics 12: 2862-2865.

Barkla BJ, Zingarelli L, Blumwald E, Smith J. 1995. Tonoplast $\mathrm{Na}^{+} / \mathrm{H}^{+}$antiport activity and its energization by the vacuolar $\mathrm{H}^{+}$-ATPase in the halophytic plant Mesembryanthemum crystallinum L. Plant Physiology 109: 549-556.

Barragán V, Leidi EO, Andrés Z, Rubio L, De Luca A, Fernández JA, Cubero B, Pardo JM. 2012. Ion exchangers NHX1 and NHX2 mediate active potassium uptake into vacuoles to regulate cell turgor and stomatal function in Arabidopsis. Plant Cell 24: 1127-1142.

Bassil E, Ohto M, Esumi T, Tajima H, Zhu Z, Cagnac O, Belmonte M, Peleg Z, Yamaguchi T, Blumwald E. 2011. The Arabidopsis intracellular $\mathrm{Na}^{+} / \mathrm{H}^{+}$ antiporters NHX5 and NHX6 are endosome associated and necessary for plant growth and development. Plant Cell 23: 224-239.

Benito B, Haro R, Amtmann A, Cuin TA, Dreyer I. 2014. The twins $\mathrm{K}^{+}$and $\mathrm{Na}^{+}$in plants. Journal of Plant Physiology 171: 723-731.

Bohnert HJ, Cushman JC. 2000. The ice plant cometh: lessons in abiotic stress tolerance. Journal of Plant Growth Regulation 19: 334-346.

Bonales-Alatorre E, Pottosin I, Shabala L, Chen Z-H, Zeng F, Jacobsen S-E, Shabala S. 2013a. Differential activity of plasma and vacuolar membrane transporters contributes to genotypic differences in salinity tolerance in a halophyte species, Chenopodium quinoa. International Journal of Molecular Sciences 14: 9267-9285.

Bonales-Alatorre E, Shabala S, Chen Z-H, Pottosin I. 2013b. Reduced tonoplast fast-activating and slow-activating channel activity is essential for conferring salinity tolerance in a facultative halophyte, quinoa. Plant Physiology 162: 940-952.

Borland AM, Hartwell J, Weston DJ, Schlauch KA, Tschaplinski TJ, Tuskan GA, Yang X, Cushman JC. 2014. Engineering crassulacean acid metabolism to improve water-use efficiency. Trends in Plant Science 19: 327-338.

Chanroj S, Lu Y, Padmanaban S, Nanatani K, Uozumi N, Rao R, Sze H. 2011. Plant-specific cation $/ \mathrm{H}^{+}$exchanger 17 and its homologs are endomembrane $\mathrm{K}^{+}$ 
transporters with roles in protein sorting. Journal of Biological Chemistry 286: 33931-33941.

Chauhan S, Forsthoefel N, Ran Y, Quigley F, Nelson DE, Bohnert HJ. 2000. $\mathrm{Na}^{+} /$myo-inositol symporters and $\mathrm{Na}^{+} / \mathrm{H}^{+}$-antiport in Mesembryanthemum crystallinum. Plant Journal 24: 511-522.

Cosentino C, Di Silvestre D, Fischer-Schliebs E, Homann U, De Palma A, Comunian C, Mauri PL, Thiel G. 2013. Proteomic analysis of Mesembryanthemum crystallinum leaf microsomal fractions finds an imbalance in V-ATPase stoichiometry during the salt-induced transition from $\mathrm{C}_{3}$ to CAM. Biochemical Journal 450: 407-415.

Cushman JC, Bohnert HJ. 1999. Crassulacean acid metabolism: molecular genetics. Annual Review of Plant Physiology and Plant Molecular Biology 50: 305-332.

Cushman JC, Tillett RL, Wood JA, Branco JM, Schlauch KA. 2008. Large-scale mRNA expression profiling in the common ice plant, Mesembryanthemum crystallinum, performing $\mathrm{C}_{3}$ photosynthesis and Crassulacean acid metabolism (CAM). Journal of Experimental Botany 59: 1875-1894.

Demidchik V, Tester M. 2002. Sodium fluxes through nonselective cation channels in the plasma membrane of protoplasts from Arabidopsis roots. Plant Physiology 128: 379-387.

Flowers TJ, Colmer TD. 2008. Salinity tolerance in halophytes. New Phytologist 179: 945-963.

Garcia de la Garma J, Fernandez-Garcia N, Bardisi E, Pallol B, Asensio-Rubio JS, Bru R, Olmos E. 2014. New insights into plant salt acclimation: the roles of vesicle trafficking and reactive oxygen species signalling in mitochondria and the endomembrane system. New Phytologist 205: 216-239.

Gong Q, Li P, Ma S, Indu Rupassara S, Bohnert HJ. 2005. Salinity stress adaptation competence in the extremophile Thellungiella halophila in comparison with its relative Arabidopsis thaliana. Plant Journal 44: 826-839.

Haas BJ, Papanicolaou A, Yassour M, Grabherr M, Blood PD, Bowden J,

Couger MB, Eccles D, Li B, Lieber M et al. 2013. De novo transcript sequence reconstruction from RNA-seq using the Trinity platform for reference generation and analysis. Nature Protocols 8: 1494-1512.

Harris NN, Javellana J, Davies KM, Lewis DH, Jameson PE, Deroles SC, Calcott KE, Gould KS, Schwinn KE. 2012. Betalain production is possible in anthocyanin-producing plant species given the presence of DOPA-dioxygenase and L-DOPA. BMC Plant Biology 12: 34.

Hedrich R, Marten I. 2011. TPC1-SV channels gain shape. Molecular Plant 4: 428-441.

Herrera A. 2009. Crassulacean acid metabolism and fitness under water deficit stress: if not for carbon gain, what is facultative CAM good for? Annals of Botany 103: 645-653.

Heyndrickx KS, Vandepoele K. 2012. Systematic identification of functional plant modules through the integration of complementary data sources. Plant Physiology 159: 884-901.

Hoagland D, Arnon D. 1950. The water-culture method for growing plants without soil. California Agricultural Experiment Station Circular 347: 1-32.

Ibdah M, Krins A, Seidlitz HK, Heller W, Strack D, Vogt T. 2002. Spectral dependence of flavonol and betacyanin accumulation in Mesembryanthemum crystallinum under enhanced ultraviolet radiation. Plant, Cell \& Environment 25: $1145-1154$.

Ishitani M, Majumder AL, Bornhouser A, Michalowski CB, Jensen RG, Bohnert HJ. 1996. Coordinate transcriptional induction of myo-inositol metabolism during environmental stress. Plant Journal 9: 537-548.

Jiao Y, Tausta SL, Gandotra N, Sun N, Liu T, Clay NK, Ceserani T, Chen M, Ma L, Holford M et al. 2009. A transcriptome atlas of rice cell types uncovers cellular, functional and developmental hierarchies. Nature Genetics 41: 258263.

Jou Y, Wang Y, Yen H. 2007. Vacuolar acidity, protein profile, and crystal composition of epidermal bladder cells of the halophyte Mesembryanthemum crystallinum. Functional Plant Biology 34: 353-359.

Kim B-G, Waadt R, Cheong YH, Pandey GK, Dominguez-Solis JR, Schültke S, Lee SC, Kudla J, Luan S. 2007. The calcium sensor CBL10 mediates salt tolerance by regulating ion homeostasis in Arabidopsis. Plant Journal 52: 473-484.

Kirch H, Vera-Estrella R, Golldack D. 2000. Expression of water channel proteins in Mesembryanthemum crystallinum. Plant Physiology 123: 111-124.
Kore-eda S, Cushman MA, Akselrod I, Bufford D, Fredrickson M, Clark E, Cushman JC. 2004. Transcript profiling of salinity stress responses by largescale expressed sequence tag analysis in Mesembryanthemum crystallinum. Gene 341: 83-92.

Kurtz S, Phillippy A, Delcher AL, Smoot M, Shumway M, Antonescu C, Salzberg SL. 2004. Versatile and open software for comparing large genomes. Genome Biology 5: R12.

Langmead B, Trapnell C, Pop M, Salzberg SL. 2009. Ultrafast and memoryefficient alignment of short DNA sequences to the human genome. Genome Biology 10: R25.

Lüttge U, Fischer E, Steudle E. 1978. Membrane potentials and salt distribution in epidermal bladders and photosynthetic tissue of Mesembryanthemum crystallinum L. Plant, Cell \& Environment 1: 121-129.

Maathuis FJM. 2014. Sodium in plants: perception, signalling, and regulation of sodium fluxes. Journal of Experimental Botany 65: 849-858.

MacRobbie E. 1999. Vesicle trafficking: a role in trans-tonoplast ion movements? Journal of Experimental Botany 50: 925-934.

Maere S, Heymans K, Kuiper M. 2005. BiNGO: a Cytoscape plugin to assess overrepresentation of gene ontology categories in biological networks. Bioinformatics 21: 3448-3449.

Mitani-Ueno N, Yamaji N, Zhao F-J, Ma JF. 2011. The aromatic/arginine selectivity filter of NIP aquaporins plays a critical role in substrate selectivity for silicon, boron, and arsenic. Journal of Experimental Botany 62: 4391-4398.

Mortazavi A, Williams BA, Mccue K, Schaeffer L, Wold B. 2008. Mapping and quantifying mammalian transcriptomes by RNA-Seq. Nature Methods 5 : 621-628.

Müller M, Kunz H-H, Schroeder JI, Kemp G, Young HS, Neuhaus HE. 2014. Decreased capacity of sodium export out of Arabidopsis chloroplasts impairs salt tolerance, photosynthesis and plant performance. Plant Journal 78: 646-658.

Neff M, Chory J. 1998. Genetic interactions between phytochrome A, phytochrome B, and cryptochrome 1 during Arabidopsis development. Plant Physiology 118: 27-36.

Nelson D, Koukoumanos M, Bohnert H. 1999. Myo-inositol-dependent sodium uptake in ice plant. Plant Physiology 119: 165-172.

Oh D-H, Hong H, Lee SY, Yun D-J, Bohnert HJ, Dassanayake M. 2014. Genome structures and transcriptomes signify niche adaptation for the multiion tolerant extremophyte Schrenkiella parvula. Plant Physiology 164: 2123-2138.

Pantoja O, Dainty J, Blumwald E. 1989. Ion channels in vacuoles from halophytes and glycophytes. FEBS Letters 255: 92-96.

Paul MJ, Cockburn W. 1989. Pinitol, a compatible solute in Mesembryanthemum crystallinum L.? Journal of Experimental Botany 40: 1093-1098.

Peiter E, Maathuis F, Mills L, Knight H. 2005. The vacuolar $\mathrm{Ca}^{2+}$-activated channel TPC1 regulates germination and stomatal movement. Nature 434: 325-337.

Peshev D, Vergauwen R, Moglia A, Hideg E, Van den Ende W. 2013. Towards understanding vacuolar antioxidant mechanisms: a role for fructans? Journal of Experimental Botany 64: 1025-1038.

Qi X, Li M-W, Xie M, Liu XX, Ni M, Shao G, Song C, Kay-Yuen Yim A, Tao Y, Wong F-L et al. 2014. Identification of a novel salt tolerance gene in wild soybean by whole-genome sequencing. Nature Communications 5: 4340.

Quan R, Lin H, Mendoza I, Zhang Y, Cao W, Yang Y, Shang M, Chen S, Pardo JM, Guo Y. 2007. SCABP8/CBL10, a putative calcium sensor, interacts with the protein kinase SOS2 to protect Arabidopsis shoots from salt stress. Plant Cell 19: 1415-1431.

Quigley F, Rosenberg JM, Shachar-Hill Y, Bohnert HJ. 2002. From genome to function: the Arabidopsis aquaporins. Genome Biology 3: research0001.10001.17

Ren X-L, Qi G-N, Feng H-Q, Zhao S, Zhao S-S, Wang Y, Wu W-H. 2013. Calcineurin B-like protein CBL10 directly interacts with AKT1 and modulates $\mathrm{K}^{+}$homeostasis in Arabidopsis. Plant Journal 74: 258-266.

Rerie WG, Feldmann KA, Marks MD. 1994. The GLABRA2 gene encodes a homeo domain protein required for normal trichome development in Arabidopsis. Genes \& Development 8: 1388-1399.

Shabala S. 2013. Learning from halophytes: physiological basis and strategies to improve abiotic stress tolerance in crops. Annals of Botany 112: 1209-1221. 
Smirnoff N, Cumbes Q. 1989. Hydroxyl radical scavenging activity of compatible solutes. Phytochemistry 28: 1057-1060.

Steudle E, Lüttge U, Jfilich K. 1975. Water relations of the epidermal bladder cells of the halophytic species Mesembryanthemum crystallinum: direct measurements of hydrostatic pressure and hydraulic conductivity. Planta 126: 229-246.

Stintzing F, Schieber A, Carle R. 2003. Evaluation of colour properties and chemical quality parameters of cactus juices. European Food Research and Technology 216: 303-311.

Su H, Balderas E, Vera-Estrella R, Golldack D, Quigley F, Zhao C, Pantoja O, Bohnert HJ. 2003. Expression of the cation transporter McHKT1 in a halophyte. Plant Molecular Biology 52: 967-980.

Tang R-J, Yang Y, Yang L, Liu H, Wang C-T, Yu M-M, Gao X-S, Zhang H-X. 2014. Poplar calcineurin B-like proteins PtCBL10A and PtCBL10B regulate shoot salt tolerance through interaction with PtSOS2 in the vacuolar membrane. Plant, Cell \& Environment 37: 573-588.

Taybi T, Patil S, Chollet R, Cushman J. 2000. A minimal serine/threonine protein kinase circadianly regulates phosphoenolpyruvate carboxylase activity in Crassulacean acid metabolism-induced leaves of the common ice plant. Plant Physiology 123: 1471-1481.

Thorvaldsdóttir H, Robinson JT, Mesirov JP. 2012. Integrative Genomics Viewer (IGV): high-performance genomics data visualization and exploration. Briefings in Bioinformatics 14: 178-192.

Vernon DM, Bohnert HJ. 1992a. A novel methyl transferase induced by osmotic stress in the facultative halophyte Mesembryanthemum crystallinum. EMBO Journal 11: 2077-2085.

Vernon DM, Bohnert HJ. 1992b. Increased expression of a myo-inositol methyl transferase in Mesembryanthemum crystallinum is part of a stress response distinct from Crassulacean acid metabolism induction. Plant Physiology 99: $1695-1698$.

Vogt T, Ibdah M, Schmidt J, Wray V, Nimtz M, Strack D. 1999. Light-induced betacyanin and flavonol accumulation in bladder cells of Mesembryanthemum crystallinum. Phytochemistry 52: 583-592.

Winter K, Holtum JAM. 2007. Environment or development? Lifetime net $\mathrm{CO}_{2}$ exchange and control of the expression of Crassulacean acid metabolism in Mesembryanthemum crystallinum. Plant Physiology 143: 98-107.

Winter K, Lüttge U, Winter E. 1978. Seasonal shift from $C_{3}$ photosynthesis to Crassulacean acid metabolism in Mesembryanthemum crystallinum growing in its natural environment. Oecologia 237: 225-237.

Yang Y, Smith SA. 2013. Optimizing de novo assembly of short-read RNA-seq data for phylogenomics. BMC Genomics 14: 328.

\section{Supporting Information}

Additional supporting information may be found in the online version of this article.

Fig. S1 Anthocyanin, betacyanin and betaxanthin content of bladder cell sap from Mesembryanthemum crystallinum.

Fig. S2 Flow chart depicting the processes in the development of a nonredundant reference transcriptome based on de novo assembly of RNA-seq reads.
Fig. S3 Networks representing gene ontology (GO) terms in the biological process (BP) category enriched in differently expressed transcription contigs (DETs).

Fig. S4 Networks representing gene ontology (GO) terms in the cellular component (CC) category enriched in differently expressed transcription contigs (DETs).

Table S1 List of contigs, annotation and RNA-seq results for the $\mathrm{McEBC}$ transcriptome

Table S2 List of gene and protein abbreviations used in Table 4

Table S3 Full list of gene ontology (GO) terms enriched in differently expressed transcription contigs (DETs) and transcript contigs included in each GO term

Table S4 Salt regulation of transcript contigs related to $\mathrm{Na}^{+}$ transport and $\mathrm{H}^{+}$gradient generation

Table S5 Salt regulation of transcripts in metabolic pathways related to osmolyte accumulation

Table S6 Salt regulation of transcript contigs in gene ontology (GO) terms related to salt and osmotic stress responses

Table S7 Salt regulation of transcript contigs involved in endoplasmic reticulum (ER) and Golgi apparatus functions

Table S8 Comparison of the McEBC transcriptome with published RNA-seq data for leaf tissues in diverse plant species

Table S9 Data used for Table S8

Table S10 List of transcript contigs shown in Fig. 7, with the intracellular localization of the encoded protein and salt response of expression in McEBCs

Please note: Wiley Blackwell are not responsible for the content or functionality of any supporting information supplied by the authors. Any queries (other than missing material) should be directed to the New Phytologist Central Office. 